\title{
Evolution of satellite derived chlorophyll-a trends in the Bohai and Yellow Seas during 2002-2018: Comparison between linear and nonlinear trends
}

\author{
Yueqi Wang ${ }^{\text {a,b,c, },}$, Xinpeng Tian ${ }^{\text {a,b,c }}$, Zhiqiang Gao ${ }^{\text {a,b,c }}$ \\ ${ }^{\text {a }}$ CAS Key Laboratory of Coastal Environmental Processes and Ecological Remediation, Yantai Institute of Coastal Zone Research, Chinese Academy of Sciences, Yantai, \\ 264003, China \\ ${ }^{\mathrm{b}}$ Shandong Key Laboratory of Coastal Environmental Processes, Yantai Institute of Coastal Zone Research, Chinese Academy of Sciences, Yantai, 264003, China \\ ${ }^{\mathrm{c}}$ Center for Ocean Mega-Science, Chinese Academy of Sciences, Qingdao, 266071, China
}

\section{A R T I C L E I N F O}

\section{Keywords:}

Long-term Chl-a trend

Linear and nonlinear

The Bohai and Yellow seas

Remote sensing

Eutrophication

\begin{abstract}
A B S T R A C T
The trends of sea surface chlorophyll-a (Chl-a) concentrations in the Bohai and Yellow Seas of China (BYS) were analysed based on the satellite-derived Chl-a dataset from August 2002 to December 2018. The result of linear trend analysis based on the seasonal Mann-Kendall test indicates a significant positive Chl-a trend during this period, with an average trend of $\sim 1.15 \%$ year $^{-1}$ (Slope: $\sim 0.011 \mathrm{mg}$ year ${ }^{-1}$ ). However, the linear trends of Chl-a varied seasonally, with strong and significant increases in spring and summer (about $2 \%$ year $^{-1}$ ), and weak and non-significant increases in winter (lower than $1 \%$ year $^{-1}$ ). The results of the ensemble empirical mode decomposition (EEMD) analysis revealed highly nonlinear and time-varying trends of Chl-a in the BYS, with gradually increased Chl-a during 2002-2011 and decreased Chl-a from 2012 to 2018. The instantaneous rate of

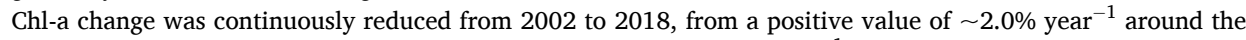
beginning year (2002) to a negative value of approximately $-2.0 \%$ year $^{-1}$ around the recent year (2018). The temporal evolution of the Chl-a trend was well in accordance with the changes in nutrient enrichment, suggesting that the status of eutrophication might be the primary driver of the long-term trends in Chl-a. The increase (decrease) in nutrient levels could alleviate (aggravate) the nutrient limitation for phytoplankton growth in spring and summer, thus regulating the changes in Chl-a. In contrast, the Chl-a trend seems to be unrelated to the trend of light intensity in this area. This is the first study aimed to discern and compare the linear and evolutionary nonlinear Chl-a trends in the BYS and provides a baseline against which future changes can be monitored.
\end{abstract}

\section{Introduction}

Marine phytoplankton produces approximately half of the global total primary production, forming the foundation of all marine ecosystems (Field et al., 1998). In the context of climate change and anthropogenic disturbance bearing on marine ecosystems, phytoplankton biomass is likely to be affected, and its dynamic need to be monitored and understood to predict the intensity and direction of future changes in fisheries and marine ecosystems (Barnett et al., 2001; Hoegh-Guldberg and Bruno, 2010; Smetacek and Cleorn, 2008). To date, the most comprehensive information on phytoplankton biomass dynamics comes from the remotely sensed chlorophyll-a (Chl-a) at high spatial-temporal resolutions and coverages (IOCCG, 2000; Joint and Groom, 2000). In the past two decades, numerous studies have used satellite-derived Chl-a to investigate the temporal and spatial dynamics of phytoplankton biomass
(Demarcq et al., 2012; Friedland et al., 2018; Gregg et al., 2005; Gregg and Rousseaux, 2014; Henson et al., 2018; Nieto and Mélin, 2017; Siegel et al., 2013; Vantrepotte and Mélin, 2011). Overall, the characteristics of Chl-a spatial distribution and seasonal variability could be well discerned by satellite observations because of their distinct features (Demarcq et al., 2012; Doney et al., 2003; Sasai et al., 2012; Werdell et al., 2009; Yoder and Kennelly, 2003). In contrast, the interannual variations and long-term trends usually account for a small fraction of the total variance in the Chl-a time series and are thus more susceptible to data biases (Beaulieu et al., 2013; Gregg and Rousseaux, 2014; Gregg et al., 2017; Hammond et al., 2017, 2018; Lamont et al., 2019; Sathyendranath et al., 2017; Vantrepotte and Mélin, 2011). For example, the satellite Chl-a algorithm errors (Cui et al., 2010; Gregg et al., 2009; Melin et al., 2007; Sathyendranath et al., 2017) and cross-mission biases (Hammond et al., 2017; Melin et al., 2017;

\footnotetext{
* Corresponding author. Yantai Institute of Coastal Zone Research, CAS, 17th Chunhui Road, Laishan District, 264003, Yantai, China.

E-mail address: yueqiwang@yic.ac.cn (Y. Wang).
} 
Sathyendranath et al., 2017; Sravanthi et al., 2017) can have significant impacts on the generation of long-term Chl-a data series (Beaulieu et al., 2013; Sathyendranath et al., 2017), thereby resulting in uncertainties in their trend estimates (Melin et al., 2017; Wang et al., 2019b). As a consequence, although there is mounting evidence that marine phytoplankton biomass changes at basin-wide (Basterretxea et al., 2018; Kahru et al., 2009; Lamont et al., 2019) and global scales (Feng and Zhu, 2012; Gregg and Rousseaux, 2014; Siegel et al., 2013), considerable uncertainties remain regarding the intensity and direction of the Chl-a trends, primarily due to the different datasets and methodologies being used (Beaulieu et al., 2013; Boyce et al., 2010, 2014; Siegel et al., 2013).

The Bohai and Yellow Seas (BYS), located in northern China, are connected by the Bohai Strait (Fig. 1a). Most of the BYS consists of a shallow continental shelf (water depth $<100 \mathrm{~m}$ ) and its marine ecosystem undergoes impacts from strong atmosphere-land-ocean interactions and severe human activities. Numerous rivers from the surrounding continents, including two of the largest rivers in the world (i.e. Yangtze River and Yellow River), flow into the BYS (Fig. 1a), supplying large amounts of freshwater and sediments, and providing substantial land-sourced nutrients to support phytoplankton growth. The East Asian monsoon associated with seasonal changes in atmospheric temperature, dominates the meteorological condition of the BYS (Wei et al., 2010; Wu et al., 2016; Zheng et al., 2017), which has a strong impact on the physical sea environment, such as water column stratification (Park et al., 2015; Tan and Shi, 2012), frontal structure (Chen, 2009; Lie et al., 2009), and current system (Mask et al., 1998; Yanagi and Takahashi, 1993). These complex physical processes regulate phytoplankton growth in the euphotic layer by influencing light availability, nutrient supply and grazing pressure, thereby affecting the dynamics of sea surface Chl-a (Liu and Wang, 2013; Wei et al., 2016). According to the theory of aquatic photosynthesis, the nutrient, light and temperature are the basic and direct environmental factors influencing the phytoplankton photosynthetic capacity in aquatic system, thus affecting the dynamics of Chl-a concentrations in the ocean (Falkowski and Raven, 2007). Therefore, no matter how complicated environmental conditions of a marine system, the changes of Chl-a could be finally attributed to the variations in nutrient, light and temperature. Over the past several decades, the BYS ecosystem has been gradually deteriorating due to the enhanced eutrophication induced by rapid economic development and population growth (Strokal et al., 2014; Tang et al., 2016; Wang et al., 2018). Therefore, the Chl-a dynamics of the BYS are of great concern and have been widely analysed based on field surveys and satellite observations (Chen and Liu, 2015; Liu and Wang, 2013; Wang et al., 2019c; Yamaguchi et al., 2012). For instance, the decrease in Chl-a from nearshore to offshore waters was mainly attributed to the reduced nutrient concentration with increasing water depth (Kim et al., 2007; Liu and Wang, 2013; Shi and Wang, 2012). The Chl-a seasonality was spatially heterogeneous with quite different seasonal cycles between the coastal and offshore waters in the BYS (Fig. 1 b and c), which was mainly attributed to the seasonal changes of various environmental drivers affecting the nutrient and light conditions (Hao et al., 2019; Kong et al., 2019; Wang et al., 2019c).

Overall, the spatial and seasonal patterns of Chl-a variability in the BYS have been widely reported, and many features were clearly delineated (Chen and Liu, 2015; Liu and Wang, 2013; Zhang et al., 2017). In contrast, the long-term Chl-a trend is poorly understood, mainly due to data constraints (Hao et al., 2019; Wang et al., 2019b). Generally, a long-term reliable Chl-a data record is essential for monitoring and understanding the evolution of Chl-a trends (Sathyendranath et al., 2017; Weatherhead et al., 2017). However, the optically complex properties of the sea water usually bias the satellite Chl-a retrievals (Melin et al., 2007; Odermatt et al., 2012; Sun et al., 2010), inevitably reducing the reliability of the conclusions (Melin et al., 2007; Odermatt et al., 2012). Therefore, some compromises have been adopted for long-term Chl-a trend analysis in the BYS. For example, the relative patterns (Fu et al., 2016; Liu and Wang, 2013) or the typical events (e.g. phytoplankton bloom) were only considered in some studies (Liu et al., 2015; Shi et al., 2017), and some other studies only focused on the Chl-a trends in summer and spring when the satellite Chl-a dataset has relatively high accuracy (Yamaguchi et al., 2012, 2013). To date, despite many efforts for Chl-a dynamics studies based on field and remotely sensed Chl-a observations, some fundamental issues on the Chl-a trends are still poorly resolved: How has Chl-a been changing in the BYS over
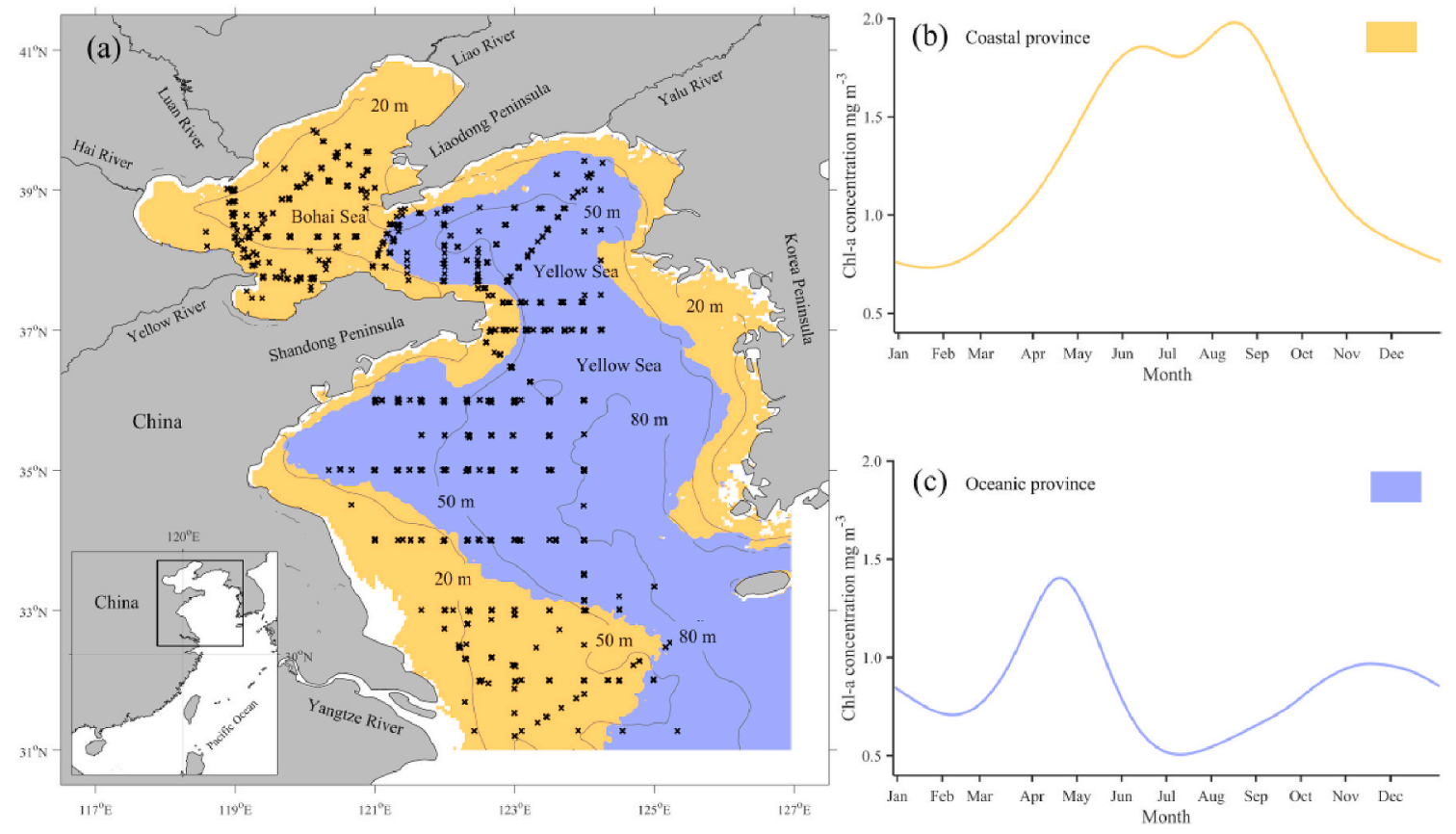

Fig. 1. (a) Geographic map of the study area and spatial distribution of the two distinct provinces (i.e. coastal province and oceanic province) obtained from the Chla seasonal cycles clustering. (b) and (c) are the corresponding averaged seasonal cycles for each province, respectively. (Hao et al., 2019; Wang and Gao, 2020). The cross marks in (a) are the locations of in situ Chl-a measurements being used for satellite Chl-a validation. 
the last decade? Are trends homogenous in pace and time? What are the potential drivers for these trends? To explore these issues, a comprehensive trend analysis, including linear and nonlinear trends, was conducted on an improved 16-year (2002-2018) satellite-derived Chl-a data record for the BYS.

With more than 16 years of reliable satellite-derived Chl-a data, it is now worthwhile to conduct an unprecedented analysis on it to provide comprehensive views of the long-term evolution of Chl-a trends in the BYS. We proceeded in three steps: (1) we addressed the direction and intensity of the overall linear Chl-a trends based on the seasonal MannKendall (MK) test, (2) we examined the time-varying nonlinear Chl-a trends based on ensemble empirical mode decomposition (EEMD) analysis, and (3) we explored the potential drivers (i.e., nutrient, light and temperature) for the long-term Chl-a trends.

\section{Data and methods}

\subsection{Datasets}

\subsubsection{In situ sea surface Chl-a measurements}

In situ sea surface Chl-a dataset was used for evaluating the accuracy of remotely sensed Chl-a. These samples were collected from nine cruises conducted during the years 2010-2016 (Fig. 1a). These cruises used the same sampling and analysis methods for Chl-a measurements. Three duplicate samples of $1000 \mathrm{ml}$ of sea water were collected using Niskin bottles from a depth of less than 5 meters and then filtered through $47 \mathrm{~mm}$ Whatman GF/F filters under low vacuum. The filters were kept in the dark at $-20{ }^{\circ} \mathrm{C}$ before laboratory analysis. In the laboratory, photosynthetic pigments were extracted with $15 \mathrm{ml}$ of $90 \%$ acetone in the dark for 24 hours at $4{ }^{\circ} \mathrm{C}$ (Lorenzen, 1967) and the Chl-a concentration was determined spectrophotometrically (TU-1800, Persee, China).

\subsubsection{Satellite-derived remote sensing reflectance}

Level 2 daily remote sensing reflectance $\left(R_{\mathrm{rs}}\right)$ images of the Moderate Resolution Imaging Spectrometer on Aqua platform (MODIS) from 1 August 2002 to 31 December 2018 and the Visible and Infrared Imaging Spectrometer on the NPP platform (VIIRS) from 1 January 2014 to 31 December 2018 for the geographic area $117^{\circ}-127^{\circ} \mathrm{E}$ by $31^{\circ}-41^{\circ} \mathrm{N}$ were downloaded at full resolution ( $1 \mathrm{~km} \times 1 \mathrm{~km}$ nominal pixel resolution) from the Goddard Space Flight Center OceanColor website (http://oc eancolor.gsfc.nasa.gov/). Because the original $R_{\mathrm{rs}}$ images were in satellite swath coordinates, we need to remap all the images onto a common regular geographic grid in order to support data composites and time series analysis pixel-by-pixel. In addition, considering the trends were calculated for each pixel, all the $R_{\mathrm{rs}}$ images of MODIS and VIIRS were finally resampled onto a common regular $1 / 24^{\circ} \times 1 / 24^{\circ}$ grid (approximately $4 \mathrm{~km} \times 4 \mathrm{~km}$ grid in the BYS) to reduce computational burden in following trends analysis.

\subsubsection{Satellite-derived sea surface Chl-a data}

A regional GAM algorithm (statistical Generalized Additive Model) was used to calculate sea surface Chl-a concentrations based on the daily $R_{\text {rs }}$ datasets (Wang et al., 2017, 2019c). Briefly, the GAM Chl-a algorithm was constructed as a stable nonlinear smoothed regression based on the GAM, with the in situ Chl-a as a response and the remotely sensed visible $R_{\mathrm{rs}}$ bands (MODIS $R_{\mathrm{rs}}$ at $412 \mathrm{~nm}, 443 \mathrm{~nm}, 469 \mathrm{~nm}, 488 \mathrm{~nm}, 531$ $\mathrm{nm}, 547 \mathrm{~nm}, 555 \mathrm{~nm}, 645 \mathrm{~nm}, 667 \mathrm{~nm}$, and $678 \mathrm{~nm}$ ) and water depth as predictors (Wang et al., 2017). As a result, daily MODIS Chl-a images from 1 August 2002 to 31 December 2018 were obtained. Then, the monthly Chl-a datasets were calculated as the median of all the daily Chl-a data, and the data interpolation empirical orthogonal function (DINEOF) method was used to fill the missing values in the monthly Chl-a dataset (Wang and Liu, 2014). Finally, a cloud-free continuous monthly Chl-a dataset with 197 temporal steps and 30227 spatial pixels was constructed from August 2002 to December 2018 for further analysis.

To assess the reliability of trend from remotely sensed GAM Chl- $a$, two methods were used for evaluation. First, the $R_{\mathrm{rs}}$ time series of VIIRS (Visible infrared Imaging Radiometer) from 1 January 2014 to 31 December 2018 were compared with MODIS $R_{\mathrm{rs}}$ for their temporal variability. Second, the other two reported Chl-a algorithms of the BYS were compared with GAM Chl-a algorithm for their performance. One is the global standard Ocean Chlorophyll-a three-band algorithm (OC3) which was calculated using a fourth-order empirical algorithm that uses the maximum ratio of $R_{\mathrm{rs}}$ at 443 and $488 \mathrm{~nm}$ with $547 \mathrm{~nm}$ (O'Reilly et al., 1998). The other one is a regional Tassan-like Chl-a product which was calculated using a two-order empirical algorithm that uses the produce of the ratio of $R_{\mathrm{rs}}$ at 443 with $555 \mathrm{~nm}$ and 412 with $490 \mathrm{~nm}$ (Siswanto et al., 2011; Yamaguchi et al., 2013). As a result, the GAM, OC3 for MODIS (OC3M), OC3 for VIIRS (OC3V) and Tanssan-like Chl-a products were obtained and compared for their performance.

\subsubsection{Satellite-derived sea surface temperature}

The satellite-derived sea surface temperature (SST) data used in this study is the NOAA's Optimum Interpolation (OI) $0.25^{\circ}$ Daily SST (also known as Reynolds 0.25 v.2) (Reynolds and Smith, 1994; Reynolds et al., 2007), which was obtained from NOAA's National Climatic Data Center (https://www.ncei.noaa.gov/data/). There are two SST analysis products developed using OI, and the product with only AVHRR infra-red satellite SST data from 1 August 2002 to 31 December 2018 was used in this study. The monthly composite SST images were generated as the mean of all daily SST images, and the grid was resampled to $1 / 24^{\circ} \times 1 / 24^{\circ}$ as the Chl-a dataset.

\subsubsection{Satellite-derived photosynthetically active radiation}

The daily satellite-derived photosynthetically active radiation (PAR) data from MODIS/Aqua were acquired from the Goddard Space Flight Center OceanColor website (http://oceancolor.gsfc.nasa.gov/) with the time spans from 1 August 2002 to 31 December 2018. The PAR products were derived using the algorithm developed by Frouin (2003). Monthly composite PAR images were generated as the mean of all daily PAR images included, and the grid was resampled to $1 / 24^{\circ} \times 1 / 24^{\circ}$ as the Chl-a dataset.

\subsubsection{Satellite-derived diffuse attenuation coefficient of PAR}

Daily images of the diffuse attenuation coefficient for the PAR ( $\left.K_{\mathrm{PAR}}\right)$ were calculated from the daily MODIS $R_{\mathrm{rs}}$ data (obtained in section 2.1.1) over the period from 1 August 2002 to 31 December 2018 using the algorithm constructed by Son and Wang (2015). The monthly composite $K_{\mathrm{PAR}}$ images were generated as the mean of all daily $K_{\mathrm{PAR}}$ images, and the grid was resampled to $1 / 24^{\circ} \times 1 / 24^{\circ}$ as the Chl-a dataset.

\subsubsection{Light availability of sea surface}

The mean light intensity $\left(I_{\mathrm{m}}\right)$ over a surface water layer with a specific water depth $D_{\mathrm{m}}$ can be calculated as (Kirk, 1994):

$I_{m}=I_{0} \times \frac{1-\mathrm{e}^{-K \times D_{m}}}{K \times D_{m}}$

where $I_{0}$ is the sea surface irradiance and $K$ is the attenuation coefficient of light in the water column.

Strictly, the mean PAR intensity in the mixed layer was commonly used to calculate the available light for phytoplankton growth, i.e. in Equation (1), $I_{0}$ was replaced by PAR, $K$ is represented by $K_{\mathrm{PAR}}$ in section 2.1.5, and $D_{\mathrm{m}}$ was determined by mixed layer depth (MLD) (Kirk, 1994; Krug et al., 2017). However, due to the lack of a high-quality long-term MLD dataset of this area, a constant value of depth (i.e. $10 \mathrm{~m}$ ) was used to calculate the sea surface mean PAR intensity $\left(I_{\mathrm{PAR}}\right)$ based on Eq. (1). Finally, the monthly $I_{\mathrm{PAR}}$ images were estimated as the mean of all the daily images included. 


\subsubsection{Nutrient enrichment of seawater}

Although many previous reports have described the spatial and temporal patterns of nutrient conditions in the Bohai Sea and/or Yellow Sea based on field surveys (Wang et al., 2003, 2018, 2019a; Xin et al., 2019), high-quality long-term basin-scale nutrient data records for the BYS are still scarce. To give a synoptic description of the long-term changes in nutrient enrichment in this area over the study period, the yearly reports of water quality levels (WQLs) for the Bohai Sea and Yellow Sea from 2002 to 2018 were obtained from the marine environment quality bulletins (a government report), published on the website of the Ministry of Natural Resources of the People's Republic of China (http://www.mnr.gov.cn/). The WQL data were summarized as an annual time series with an area for each WQL, which was established according to the nutrient concentrations from field surveys. These field surveys were performed every summer and winter since 2001 , as previously described by Wei et al. (2015) and Yang et al. (2018). According to the WQL data and the corresponding limits of total inorganic nitrogen (TIN-N) and active phosphorus (PO4-P) for each WQL as shown in Table 1 (Xing et al., 2015), an approximate nutrient enrichment index (NEI) for reflecting nutrient status can be roughly calculated as

$\mathrm{NEI}=\sum_{i=2}^{5} N_{i} \times P_{i} \times A_{i}$

where $i$ is the level of the polluted waters, $N_{\mathrm{i}}$ is the lower limit of TIN-N concentration at level $i, P_{\mathrm{i}}$ is the lower limit of PO4-P concentration at level $i$ (Table 1 ), and $A_{\mathrm{i}}$ is the sum of reported areas $\left(\mathrm{km}^{2}\right)$ at level $i$ over the BYS. Because the WQL data were published annually, only an annual time series of NEI was calculated.

\subsection{Methods}

\subsubsection{Seasonal Mann-Kendall test}

The non-parametric seasonal MK trend test was applied to detect linear trends in the monthly Chl-a time series (Hirsch and Slack, 1984; Hirsch et al., 1982), with consideration of the significant skewed distribution of Chl-a values and the strong serial autocorrelation in the monthly Chl-a time series (Campbell, 1995; Saulquin et al., 2013), the magnitudes of trends were computed using Sens's method (Gilbert, 1987; Sen, 1968).

As a robust and non-parametric method, the MK test has been widely used to evaluate trends in geographical variables, including the sea surface Chl-a, in previous studies (Colella et al., 2016; Vantrepotte and Mélin, 2011). The test is based on the computation of a suite of MK statistics (S) applied to each separated month $m$, which are then determine the presence of long-term monotonic changes in the original time series (Hirsch et al., 1982), $\boldsymbol{S}$ is defined as

$S=\sum_{i=1}^{n m-1} \sum_{j=i+1}^{n m} \operatorname{sgn}\left(x_{j m}-x_{i m}\right)$

$\operatorname{sgn}\left(x_{j m}-x_{i m}\right)=\left\{\begin{array}{c}1 \text { if } x_{j m}-x_{i m}>0 \\ 0 \text { if } x_{j m}-x_{i m}=0 \\ -1 \text { if } x_{j m}-x_{i m}<0\end{array}\right.$

where $x$ is the value of the time series, and $n m$ is the number of datasets for month $m$. Then, the overall statistic $S^{\prime}$ is computed as the sum of the monthly S:

Table 1

TIN-N and PO4-P concentration used for the calculation of NEI.

\begin{tabular}{|c|c|c|c|c|}
\hline Water quality level & II & III & IV & $\mathrm{V}$ \\
\hline TIN-N (mg L ${ }^{-1}$ ) & 0.2 & 0.3 & 0.4 & 0.5 \\
\hline PO4-P $\left(\mathrm{mg} \mathrm{L}^{-1}\right)$ & 0.015 & 0.030 & 0.030 & 0.045 \\
\hline
\end{tabular}

$S^{\prime}=\sum_{j}^{p} s_{j}$

where $S_{\mathrm{j}}$ is the $S$-statistic for month $j$ with $j=1,2, \ldots, p$ ( $p=12$ for monthly data series of this study); see Eq. (3). When no serial dependence is exhibited in the time series, the variance of $S^{\prime}$ is defined as

$\sigma_{s}^{2}=\sum_{j=1}^{p} \operatorname{Var}\left(S_{j}^{\prime}\right)$

When a serial correlation is present, as in the case of monthly time series processes, the variance of $S^{\prime}$ is defined as (Hirsch and Slack, 1984; Van Gelder et al., 2008)

$\sigma_{s}^{2}=\sum_{j=1}^{p} \operatorname{Var}\left(S_{j}^{\prime}\right)+\sum_{g=1}^{p-1} \sum_{h=g+1}^{p} \sigma_{g h}$

where $\sigma_{g h}$ denotes the covariance between the MK statistic for season $g$ and the MK statistic for season h. The covariance $\sigma_{g h}$ could be estimated using the procedures introduced in Hirsch et al. (1982) and Van Gelder et al. (2008). Then, under the null hypothesis and for a large dataset, a normal distribution of mean 0 , and variance $\operatorname{Var}\left(S^{\prime}\right)$, the statistical significance of the trend is indicated by the $Z$ value, defined as (Hirsch et al., 1982)

$Z=\left\{\begin{array}{l}\frac{S^{\prime}-1}{\sigma_{S^{\prime}}} \text { if } S^{\prime}>0 \\ 0 \quad \text { if } S^{\prime}=0 \\ \frac{S^{\prime}-1}{\sigma_{S^{\prime}}} \text { if } S^{\prime}<0\end{array}\right.$

A positive value for $Z$ indicates an overall upward trend while a negative value reveals an overall downwards trend in the series. If $|Z|$ is greater than $Z_{1-\alpha / 2}$ at the chosen significance level $\alpha$, the trend is significant. In this study, the corresponding $p$ value of a $Z$ score can be obtained from the normal probability table, and the trend was defined as significant when $p$ value lower than $0.05(p<0.05)$.

The magnitude of trend $(\beta)$ can be determined as the median of the individual slopes of each monthly sub-sample (Hirsch et al., 1982; Sen, 1968):

$\beta=\operatorname{median}\left[\frac{x_{j m}-x_{i m}}{j-i}\right]$.

The trend was originally expressed as the slope of Chl-a change per year (unit: $\mathrm{mg} \mathrm{m}^{-3} \mathrm{Year}^{-1}$ ). To better compare the trends for Chl-a time series with different levels of Chl-a concentration, the relative linear trends (unit: $\%$ year $^{-1}$ ) could be estimated by dividing the slope ( $\beta$ ) by the initial values of the fitted line.

\subsubsection{Ensemble empirical mode decomposition}

The nonlinear trend of Chl-a was derived using the EEMD approach, an advanced adaptive data analysis method that has already been successfully used in geophysical research (Bai et al., 2017; Ji et al., 2014; Wu et al., 2007, 2009). In EEMD, a time series (Y) is decomposed adaptively into a series of amplitude-frequency modulated oscillatory components $C_{\mathrm{j}}(\mathrm{j}=1,2, \ldots, \mathrm{n})$ from high-frequency to low-frequency and a residual trend $R_{\mathrm{n}}$, which is expressed as

$\mathrm{Y}(t)=\sum_{j=1}^{n} C_{j}(t)+R_{n}(t)$

where $R_{\mathrm{n}}$ is the time-varying trend, which is an intrinsically fitted monotonic function or a function with at most one extremum within the time span. The trend follows no priori functional form and varies with time after the intrinsic variability of multi-decadal and shorter 
timescales is removed; it also has low sensitivity to extension (addition) of new data (Ji et al., 2014; Wu et al., 2007).

For multidimensional spatial-temporal datasets, the similar timescale components of the data series from all grids were pieced together to obtain the temporal evolution of the spatially coherent features of that timescale. This is an update of the EEMD method, which is called multidimensional ensemble empirical mode decomposition (MEEMD) (Ji et al., 2014; Wu et al., 2009; Zhang et al., 2018). The MEEMD result could present both the spatial and temporal local information due to its adaptiveness and locality, which enable us to reveal the hidden nonlinear and nonstationary nature of a time series. Detailed information can be found in Wu et al. (2009).

To examine the long-term evolution of the trend on decadal timescales or longer, we only focus on the residual trend $R_{\mathrm{n}}$ after adaptively removing all the $C_{\mathrm{j}}$ contained in the data series. The EEMD residual trend in a given year is defined as the mean $R_{\mathrm{n}}$ in the year. In addition, the instantaneous relative changing rate (IR) at time $t$ is determined as

$I R(\mathrm{t})=\frac{d f\left(R_{n}(t)\right)}{R_{n}(t)} \times 100 \%$.

where $d f$ denotes the temporal derivative. IR is expressed as the proportion of the change to facilitate region-to-region comparisons.

\subsubsection{Methodologies summary}

This study refers to many materials and methodologies from previous works; therefore, it is best to provide a brief summary of these schemes. First, the daily satellite-derived Chl-a, SST, $I_{\mathrm{PAR}}$ datasets were obtained based on the regional algorithms and their monthly data series were assembled as median for Chl-a and mean for the other variables. The median was used for Chl-a composite due to its log-normally distributed values (Campbell, 1995), while the mean was used for other variables composites due to their normal distribution. Second, the annual time series of NEI was only obtained because the WQL data were published annually. The NEI only represents the overall nutrient status of the whole BYS, including coastal and offshore waters. Third, both the linear trend (obtained from MK) and nonlinear trend evolution (obtained from EEMD) were analysed and compared. The linear trend represents an overall change in the study period with constant magnitude and direction, while the nonlinear trend represents instantaneous change in the study period with time-varying magnitude or direction. Fourth, for seasonal linear trend analysis, the seasonal data series was constructed as the average of the monthly data series in each season. In this study, the spring, summer, autumn, and winter were defined as March to May, June to August, September to November, and December to the next February, respectively. For example, the Chl-a value for spring 2011 was calculated as the median Chl-a values in March, April and May of 2011. Therefore, the spring data series from 2003 to 2018 was constructed with 16 time steps.

\section{Results}

\subsection{Validation of satellite Chl-a}

The satellite Chl-a estimates using regional GAM, Tassan-like and OC3M were compared with the in situ Chl-a observations for statistically evaluating and comparing their performance, as shown in Fig. 2. Fig. 2 shows the scatter plots and the corresponding metrics (root mean square error (RMSE) and determination coefficient $\left(R^{2}\right)$ ) for the 209 pairs of in situ versus satellite Chl-a estimates. Obviously, the GAM Chl-a is the most accurate product among the three considered products with an RMSE of 0.21 and $R^{2}$ of 0.66 (Fig. 2). The results suggested that the GAM Chl-a was relatively reliable, which was considered generally more suitable than other Chl-a products for further studies of the Chl-a dynamics in the BYS.

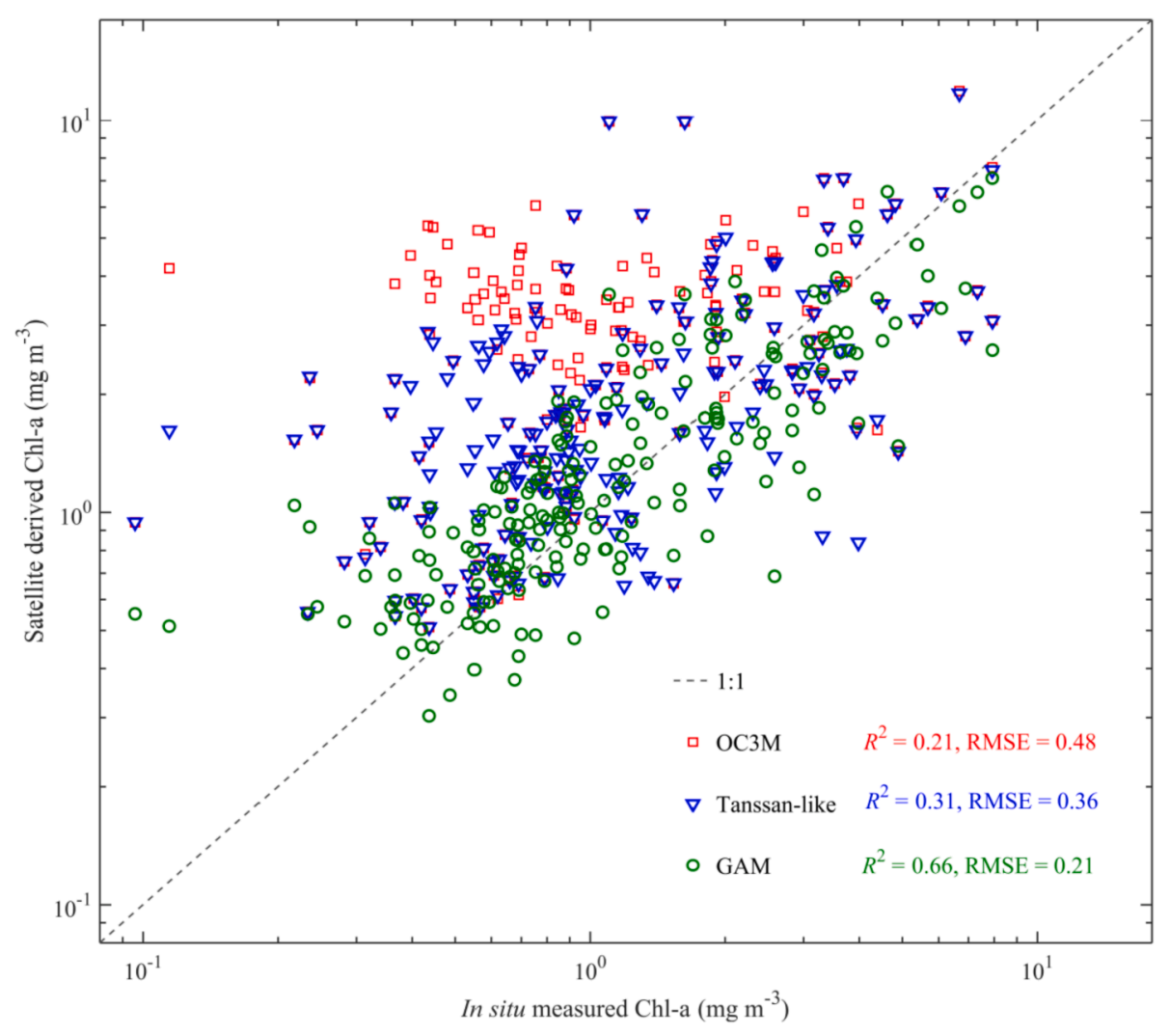

Fig. 2. Comparison of in situ Chl-a and satellite derived Chl-a for GAM, Tassan-like and OC3M. The statistical metrics (coefficients of determination $\left(R^{2}\right)$ and root mean squared error (RMSE)) for each algorithm are also given in the figure. 


\subsection{Linear trends in Chl-a}

The linear trend of Chl-a in the BYS during 2002-2018 was analysed based on the seasonal MK trend analysis. First, the basin-wide distributions of the linear trends in monthly Chl-a time series were summarized and compared across different seasons. Then, the linear trends for the region-averaged Chl-a series of the entire BYS and two sub-provinces (delineated in Fig. 1) were calculated and compared.

\subsubsection{Basin-wide distribution of linear trends and seasonal differences}

The spatial distribution of linear trends for Chl-a during 2002-2018 are shown in Fig. 3, in which Fig. 3a shows the linear Chl-a slopes (expressed in $\mathrm{mg} \mathrm{m}^{-3}$ year $^{-1}$ ), Fig. 3b shows the relative Chl-a trends (expressed in $\%$ year $^{-1}$ ), and Fig. $3 \mathrm{c}$ shows the climatological Chl-a map from 2002 to 2018. Overall, positive Chl-a trends were found in most of the BYS (87.33\% of the area) and negative Chl-a trends only occupied $12.67 \%$ of the area. Thereinto, only $44.37 \%$ of the area presented significant linear trends (including positive and negative), in which significant positive and negative trends occupied $42.73 \%$ and $1.64 \%$ of the basin, respectively. The strong positive Chl-a trends mainly prevail in the western and central parts of the Yellow Sea and along the coast of the Bohai Sea, while only some small patches near the coastline present significant negative trends of Chl-a (Fig. 3b).

Fig. 4 shows the spatial distributions of Chl-a linear trends across different seasons from 2002 to 2018 . The spatial patterns of linear trends in Chl-a varied in different seasons. Overall, the positive Chl-a trend dominates each season, with obviously higher rates in spring and summer than that in autumn and winter (Fig. 4). In spring and summer, the Chl-a trends were generally higher than $1 \%$ year $^{-1}$, which is approximately parallel to the slope of $0.01 \mathrm{mg} \mathrm{m}^{-3}$ year $^{-1}$. In autumn and winter, the Chl-a trends were generally lower than $0.5 \%$ year $^{-1}$, which is approximately parallel to the slope of $0.005 \mathrm{mg}^{-1}$ year $^{-1}$. It is noticeable that some coastal water patches present weak negative Chl-a trends in autumn and winter (Fig. 4).

\subsubsection{Region-specific linear trends and seasonal differences}

The regionally averaged Chl-a series associated with their linear trends for the entire, coastal and oceanic provinces are plotted in Fig. 5. All of the three regions demonstrated obviously increased Chl-a from 2002 to 2018 , with the trends of $1.15 \%$ year $^{-1}(p<0.05), 0.66 \%$ year $^{-1}$ $(p>0.05)$ and $1.31 \% \operatorname{year}^{-1}(p<0.05)$, respectively, for the entire, coastal and oceanic provinces. Table 2 summarises the overall and seasonal aspects of the linear trends in Chl-a for the three different regions. The most evident feature is that Chl-a increased over all seasons, but was only significant for the entire and oceanic regions in spring and summer. For the entire basin, the strongest Chl-a increase was detected in spring, with a trend of $2.14 \%$ year $^{-1}(p<0.05)$, followed by summer $\left(1.30 \%\right.$ year $\left.^{-1}, p<0.05\right)$ and autumn $\left(1.12 \%\right.$ year $\left.^{-1}, p>0.05\right)$, while the minimum Chl-a increase was present in winter with a trend of $0.60 \%$ year $^{-1}$, which is statistically insignificant (Table 2). The coastal province had the strongest Chl-a increase in spring $\left(1.90 \%\right.$ year $\left.^{-1}, p<0.05\right)$ while the lowest increase in winter $\left(0.43 \%\right.$ year $\left.^{-1}, p>0.05\right)$; however, none of the trends for the individual seasons were statistically significant (Table 2). For the oceanic province, Chl-a had the strongest increase during spring and summer with the significant trends of $3.57 \%$ year $^{-1}$ and $1.98 \%$ year $^{-1}(p<0.05)$, respectively. Overall, Chl-a had a significant positive trend during spring and summer for the BYS as a whole, while a weak but non-significant increase was found in autumn and winter. Comparing the two sub-regions, although both of them present positive Chl-a trends throughout the seasons, the strong and significant Chl-a increases were only found over the oceanic province during spring and summer (Table 2).

\subsection{Non-linear trends in Chl-a}

The evolution of nonlinear Chl-a trends was diagnosed using the EEMD approach, with residual $R_{\mathrm{n}}$ in Eq. (10) characterises the nonlinear evolution of trends and $I R_{\mathrm{n}}$ in Eq. (11) illustrates time-varying instantaneous rates of Chl-a changes. First, a basin-wide view of nonlinear trend was examined. Then, the nonlinear trend evolution of the regionaveraged Chl-a series for the entire basin and the coastal and oceanic provinces were analysed for comparisons.

\subsubsection{Basin-wide nonlinear trends in Chl-a}

The nonlinear trends of Chl-a are interpreted in Figs. 6 and 7. Fig. 6 demonstrates the averaged EEMD residuals $\left(R_{\mathrm{n}}\right.$ in Eq. (10)) for each year (the incomplete year of 2002 was not shown), which mainly delineates the overall spatial evolution of Chl-a concentrations. First, the distributions of Chl-a $R_{\mathrm{n}}$ exhibit noticeable spatial heterogeneity with generally high values in coastal waters and relatively low values in open waters, which demonstrate higher Chl-a concentrations in coastal waters than in offshore waters, as reported in many previous reports (Hao et al., 2019; Liu and Wang, 2013). The Chl-a gradient with elevated values in coastal areas to low values in oceanic waters persisted all throughout the years, but gradually weakened after 2011 (Fig. 6). The instantaneous rates of Chl-a trends for each year are shown in Fig. 7a-p. The linear trend from the MK analysis is also shown in Fig. 7q for easy interpretation and comparison between the linear and non-linear trends of Chl-a. The rates of Chl-a trends are clearly temporally variable over almost all parts of the basin, with generally weakening positive rates from 2003 to 2011 and enhancing negative rates from 2012 to 2018 (Fig. 7a-p). There are some sporadic patches in oceanic waters of the Yellow Sea and the
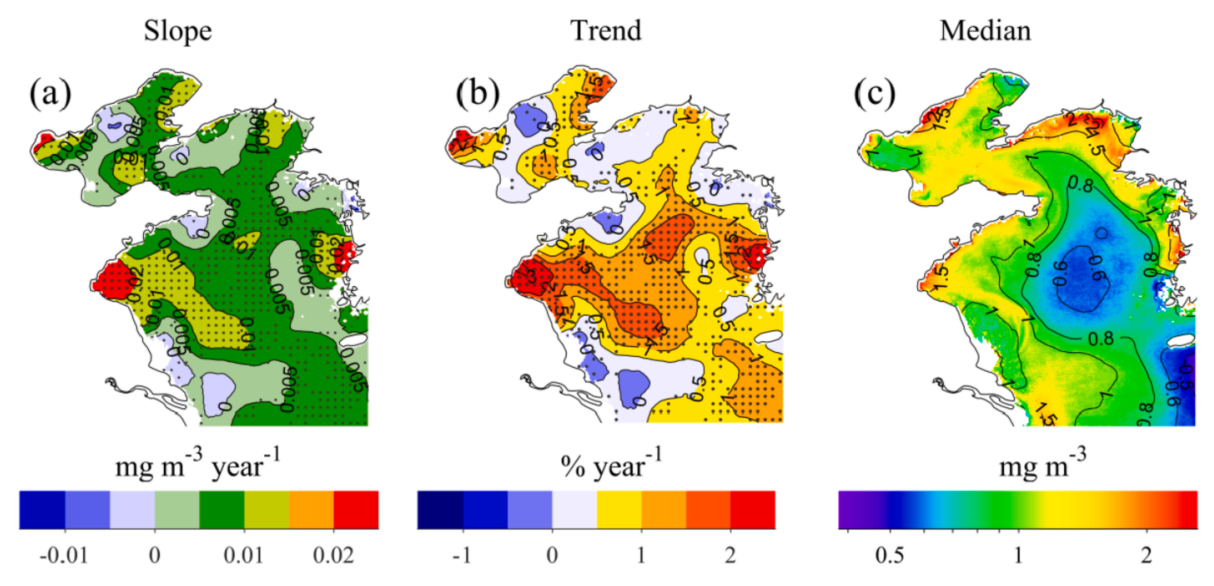

Fig. 3. Linear trends of Chl-a in the BYS for the period 2002-2018. (a) The Slope and (b) trend of Chl-a based on the MK trend analysis. (c) The climatological composite of Chl-a concentration over the whole study period. Regions with significant linear trend at the $95 \%$ confidence level are marked as gray points in (a) and (b) on a $0.25^{\circ} \times 0.25^{\circ}$ grid for clarity. 

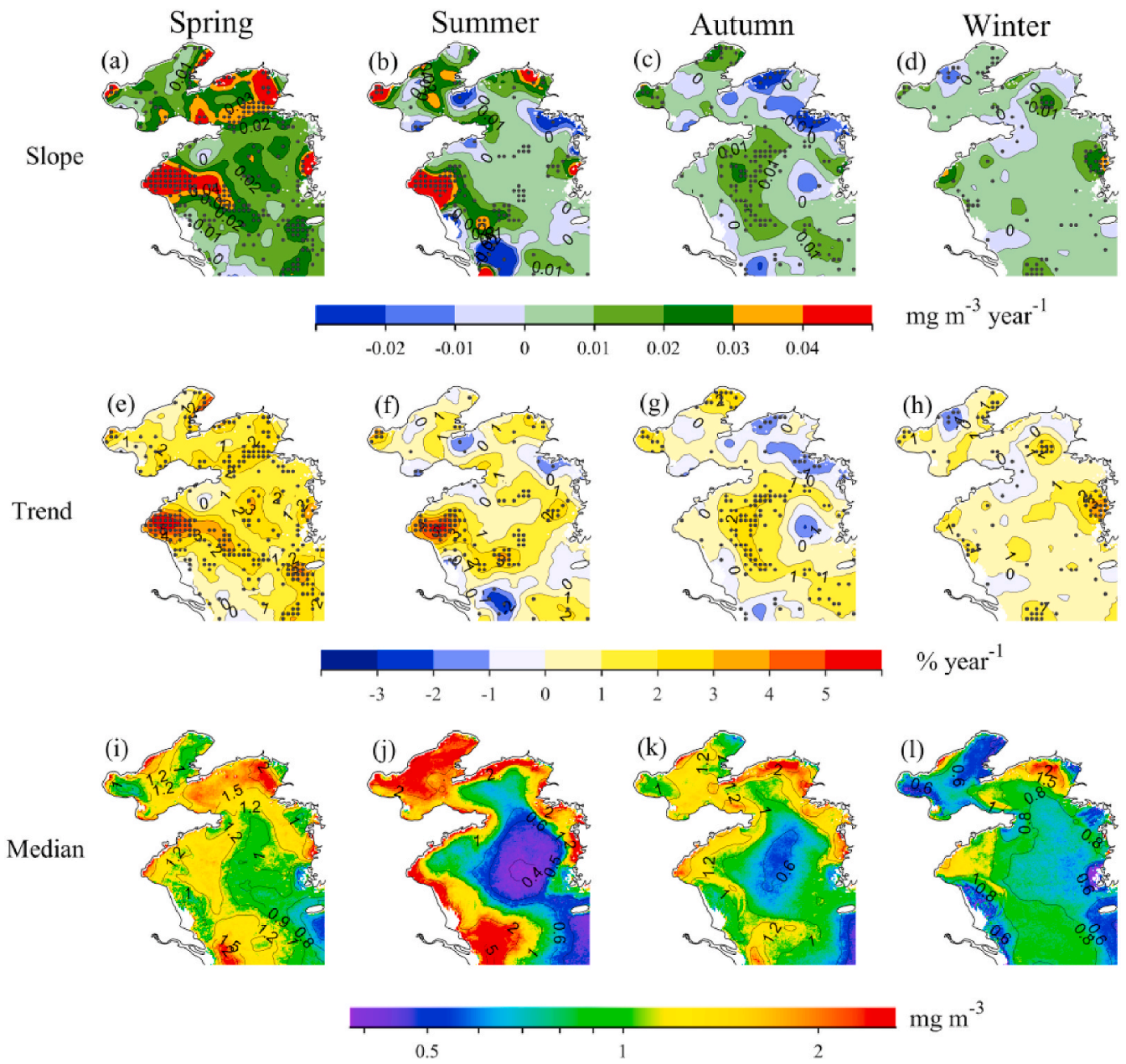

Fig. 4. Linear trends of Chl-a for the different seasons. (a, b, c and d) The slopes and (e, f, g, and h) trends of Chl-a based on the linear trend analysis. (i, j, k, and l) The seasonal Chl-a composites over the whole study period. Regions with significant linear trend at the $95 \%$ confidence level are marked as gray points in (a, b, c and d) and (e, f, g, and h) on a $0.25^{\circ} \times 0.25^{\circ}$ grid for clarity.

south-eastern part of the basin that present persistently positive trends throughout the study period (Fig. 7). These regions always present strong positive trends in view of the Chl-a linear trend (Fig. 7q). In comparison, the spatial structures of the Chl-a rates for specific years (Fig. 7a-p) are quite different from the spatial pattern of overall linear trends obtained by MK trend analysis during 2002-2018 (Fig. 7q). Apparently, these spatiotemporal evolutions of the Chl-a trends may not be clearly delineated by the linear trend analysis (Fig. 7q).

\subsubsection{Region-specific non-linear trends in Chl-a}

The non-linear EEMD residuals and the corresponding instantaneous rates of the regionally averaged Chl-a series for the entire, coastal, and oceanic provinces were plotted and compared in Fig. 8, for a comprehensive understanding and interpretation of the potential mechanisms. The time-varying trends were evident for all three region-specific Chl-a series. All Chl-a series were characterised by an increasing trend initially around 2003 and then a decreasing trend at specific years (Fig. 8). However, the timings of turning points (defined as a local minimum/ maximum in the EEMD residual trend and the instantaneous trend is equal to zero) were different among the Chl-a series for different regions. The inflection date was earlier for the coastal region (approximately in 2010) than that for the oceanic region (approximately in 2015).

\subsection{Trends in environmental drivers}

It was well established that phytoplankton growth in water is basically governed by SST, light availability and nutrient supply (Falkowski and Raven, 2007); therefore, we analysed the trends of SST, sea surface light intensity $\left(I_{\mathrm{PAR}}\right)$, and nutrient enrichment (indicated by NEI) to determine whether there were significant trends in these variables during the study period.

\subsubsection{Trends in SST}

Table 3 presents the linear trends of the averaged SST time series for the entire BYS and the two sub-regions across different seasons. The SST demonstrates significant warming trends for all the three regions, with slopes of $0.027^{\circ} \mathrm{C}_{\text {year }}{ }^{-1}, 0.028^{\circ} \mathrm{C}_{\text {year }}{ }^{-1}$ and $0.030{ }^{\circ} \mathrm{C}$ year ${ }^{-1}$ for the entire, coastal, and oceanic provinces, respectively (Table 3 ). However, considering seasonal differences, there was no significant trend detected in a single season, despite the high slopes of SST changes presented in some seasons (Table 3). The nonlinear trends of SST from EEMD analysis for the different regionally averaged time series are delineated in Fig. 9. Significant nonlinear features were found in all SST time series with continuously increasing rates (Fig. 9). All three SST series presented similar patterns with a deceasing trend before 2010 and increasing trend after 2010. This pattern is consistent with the well-known global sea surface warming hiatus over the last two decades ( $\mathrm{Hu}$ and Fedorov, 2017; Kosaka and Xie, 2013; Trenberth and Fasullo, 2013). Several studies have reported that the global warming hiatus also appeared in the BYS and its origin was complicated, and was mainly attributed to the 60-year-quasi-periodic natural climate variability of the Pacific decadal oscillation (PDO) (Li et al., 2019; Tollefson, 2014). In brief, since 1998, 

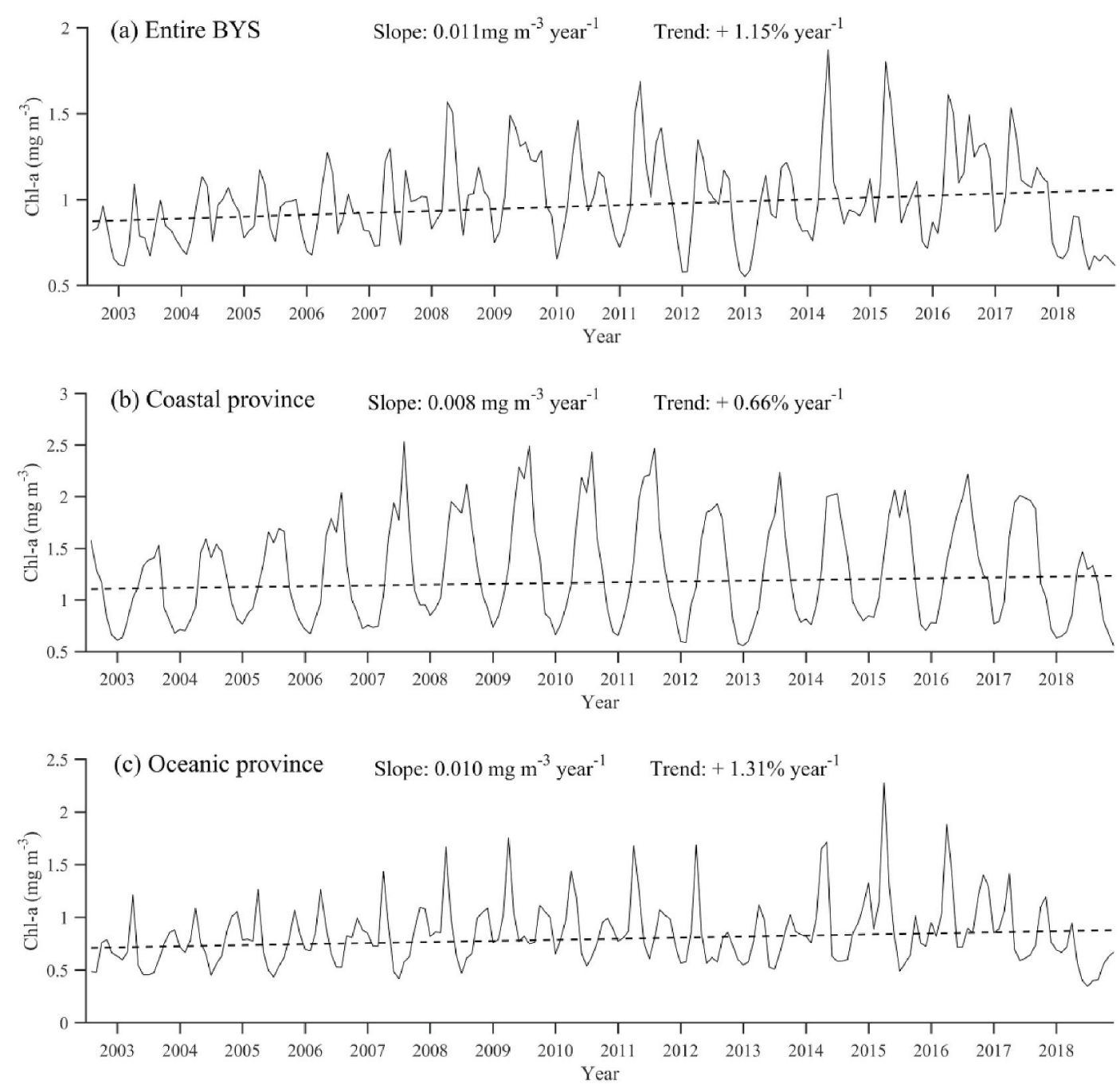

Fig. 5. Time series (solid line) and the corresponding linear trends (dashed line) of monthly Chl-a for the (a) entire, (b) coastal, and (c) oceanic regions. The slopes and relative rates are also given in the figure.

Table 2

Trends of Chl-a in different seasons for the different regions.

\begin{tabular}{lllll}
\hline Season & $\begin{array}{l}\text { Chl-a mean } \\
\left.(\mathrm{mg} \mathrm{m})^{-3}\right)\end{array}$ & $\begin{array}{l}\text { Slope } \\
\left(\mathrm{mg} \mathrm{m}{ }^{-3} \text { Year }^{-1}\right)\end{array}$ & $\begin{array}{l}\text { Relative rate } \\
\left(\% \text { Year }^{-1}\right)\end{array}$ & $p$-value \\
\hline *Overall & 0.98 & 0.011 & 1.15 & 0.001 \\
*Spring & 1.19 & 0.026 & 2.14 & 0.049 \\
*Summer & 1.00 & 0.013 & 1.30 & 0.015 \\
Autumn & 1.03 & 0.012 & 1.12 & 0.118 \\
Winter & 0.79 & 0.005 & 0.60 & 0.368 \\
Overall & 1.24 & 0.008 & 0.66 & 0.120 \\
Spring & 1.22 & 0.023 & 1.90 & 0.150 \\
Summer & 1.99 & 0.013 & 0.72 & 0.471 \\
Autumn & 1.24 & 0.006 & 0.49 & 0.365 \\
Winter & 0.75 & 0.003 & 0.43 & 0.653 \\
*Overall & 0.82 & 0.010 & 1.31 & 0.004 \\
*Spring & 1.08 & 0.038 & 3.57 & 0.032 \\
*Summer & 0.60 & 0.006 & 1.98 & 0.048 \\
Autumn & 0.86 & 0.012 & 1.42 & 0.138 \\
Winter & 0.81 & 0.007 & 0.89 & 0.528 \\
\hline
\end{tabular}

Note: the superscript (*) denotes significant linear trend.

the PDO has switched from the warm phase to the cool phase, which enhances the East Asian monsoon and deepens the East Asian trough, driving the decline in SST during 1998-2013 (Li et al., 2019). After 2013, an extreme and prolonged El Niño that occurred around 2015 ended the warming hiatus and recovered the subsequent temperature rise through atmospheric heat release (Hu and Fedorov, 2017).

\subsubsection{Trends in sea surface light availability}

Table 4 presents the linear trends in the regionally averaged $I_{\mathrm{PAR}}$ for the entire BYS and the two sub-regions across different seasons. There were no significant trends in $I_{\mathrm{PAR}}$ for any of the three $I_{\mathrm{PAR}}$ time series, as well as across all seasons (Table 4). Although no significant trend was found in $I_{\mathrm{PAR}}$ as shown in Table 4, the directions of trends exhibit some regular patterns. First, an overall positive trend was found in the $I_{\mathrm{PAR}}$ time series for the entire and coastal provinces, while an overall negative trend was present in the $I_{\mathrm{PAR}}$ time series for the oceanic province. When distinguishing based on seasons, the $I_{\mathrm{PAR}}$ in summer had positive trends, while $I_{\mathrm{PAR}}$ in autumn and winter had negative trends. The non-linear trends of $I_{\mathrm{PAR}}$ from EEMD analysis for different regions are shown in Fig. 10. All three $I_{\text {PAR }}$ time series present similar patterns with initially slight decreases and then shift to a rapid increase around 2011.

\subsubsection{Trends in nutrient enrichment}

The nutrient enrichment indicated by NEI is shown in Fig. 11. Despite fluctuating variations, an overall positive trend $\left(0.66 \%\right.$ year $\left.^{-1}\right)$ was found during 2002-2018. A distinct nonlinear evolution of NEI was obtained from EEMD analysis (Fig. 11a), with a turning date approximately in 2012 (Fig. 11b). A significant positive trend of NEI (7.34\% year $^{-1}$ ) was detected during 2002-2012, while a significant negative trend $\left(-13.60 \%\right.$ year $\left.^{-1}\right)$ was found during $2012-2018$. The increase in 

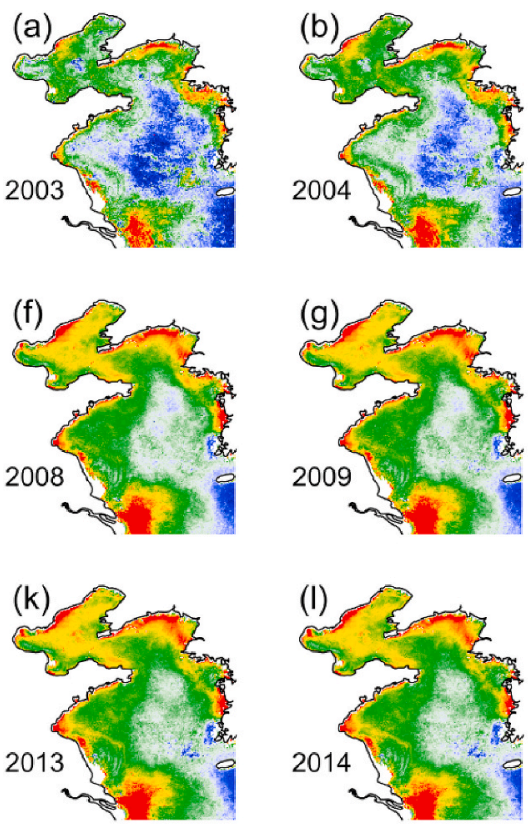
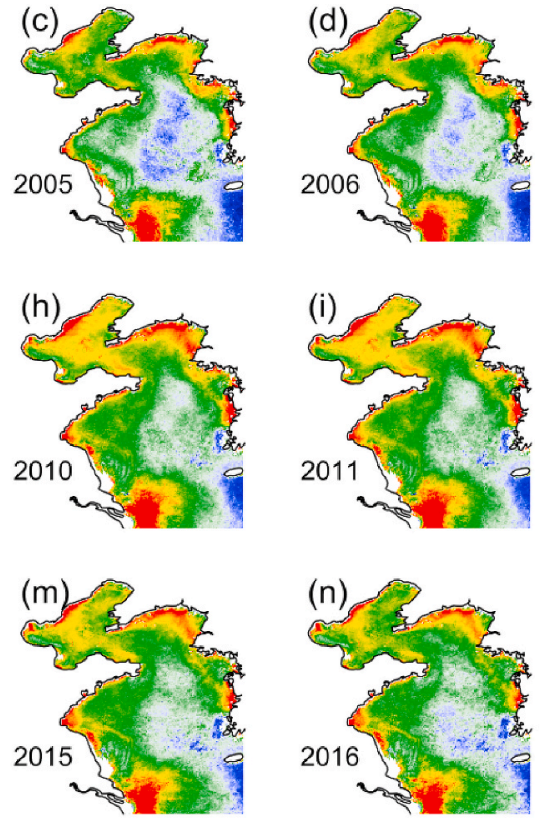
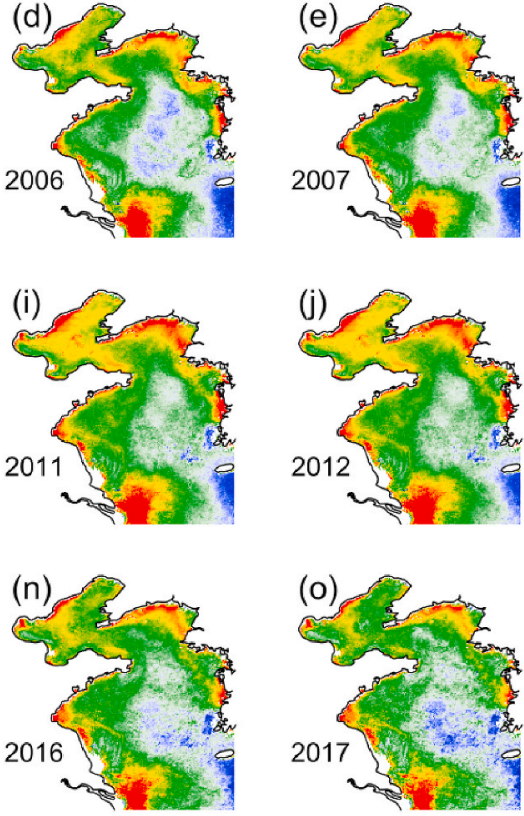
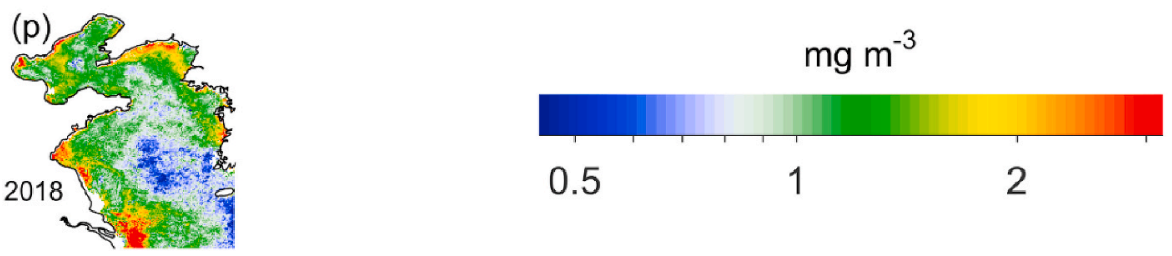

Fig. 6. Spatial and temporal patterns of the Chl-a EEMD trends in different years over the BYS.

nutrient levels since the beginning of the 2000s is a well-known phenomenon for the BYS, which was closely related to the significant variations in nutrient inputs from natural changes and human activities in which the terrestrial sources played the most important roles (Wang et al. 2018, 2019; Xin et al., 2019; Yang et al., 2018). Since the beginning of the 2010s, the promotion of green development has led to the implementation of a series of control measures to reduce nutrient emissions from terrestrial sources, which have effectively curbed the worsening trend in coastal eutrophication in Chinese seas (Xiao and Zhao, 2017). Therefore, the trend shift in the NEI index from increasing to decreasing around 2012 confirmed the continuous improvement in water quality during recent years for the BYS (Wang et al., 2018).

\section{Discussion}

\subsection{Considerations of uncertainties}

The detection of long-term changes in marine phytoplankton biomass is quite a challenging task due to many uncertainties including artifact sources from dataset acquisition and method adoption as well as the complexity of phytoplankton dynamics in which the long-term trend commonly accounts for a small fraction of the total variance in the Chl-a changes; thus, it is highly susceptible to uncertainties (Rykaczewski and Dunne, 2011; Siegel et al., 2013). Therefore, caution should be exercise when drawing conclusions. We must acknowledge that the satellite GAM Chl-a product is still not a perfect dataset with the $R^{2}$ and RMSE between in situ and satellite observations were approximately 0.7 and 0.2 , respectively (Fig. 2). However, compared with the widely used global standard OC3 algorithm (O'Reilly et al., 1998) and regional Tassan-like algorithm (Siswanto et al., 2011), the accuracy of GAM Chl-a was indeed improved (Fig. 2). Whether the GAM Chl-a could reflect the long-term trends in phytoplankton biomass still need further validation with more in situ observations accumulation in the future, up to date, it might be our best dataset choice for long-term Chl-a changes analysis in the BYS.

Addressing the declining trend of Chl-a in recent years (2012-2018) is the major contribution of this study. Therefore, the reliability of the Chl-a trend during this period should be seriously evaluated by considering the recent MODIS sensor ageing and algorithm modification (Meister and Franz, 2014; Meister et al., 2012) to evaluated if the significant Chl-a decline trend is caused by natural variability? or spurious information resulting from data errors. To address this issue, two VIIRS $R_{\mathrm{rs}}$ time series in visible band were compared with the MODIS $R_{\mathrm{rs}}$ (Fig. 12, only $R_{\mathrm{rs}} 443$ and $R_{\mathrm{rs}} 555$ were shown as examples). The results indicate good consistency in the variabilities and trends of the MODIS $R_{\mathrm{rs}}$ and VIIRS $R_{\mathrm{rs}}$ during their common period from January 2014 to December 2018. Moreover, the time series of GAM Chl-a were compared with the OC3M, OC3V and Tassan-like Chl-a time series for examining their variability (Fig. 13). Despite of distinct difference in seasonal patterns, a similar declining Chl-a trend was also found in these Chl-a series during their common period from January 2014 to December 2018 (Fig. 13). In addition, there are obvious biases between GAM and other Chl-a products across different seasons, particular in winter (Fig. 13). The lower values of GAM Chl-a than other Chl-a in winter exactly demonstrate the advantage of GAM Chl-a algorithm in alleviating overestimation of Chl-a values in winter (Wang et al., 2019c). To address the confidence of trends analysis in individual season, we statistically compared the trends from GAM and OC3M Chl-a time series in different seasons during 2014-2018, and found that there were no significant differences between the trends from the two data sources in all seasons (statistical $t$-test: $p>0.05$ ). These results enhance the confidence of our trend analysis during recent years in this study. 

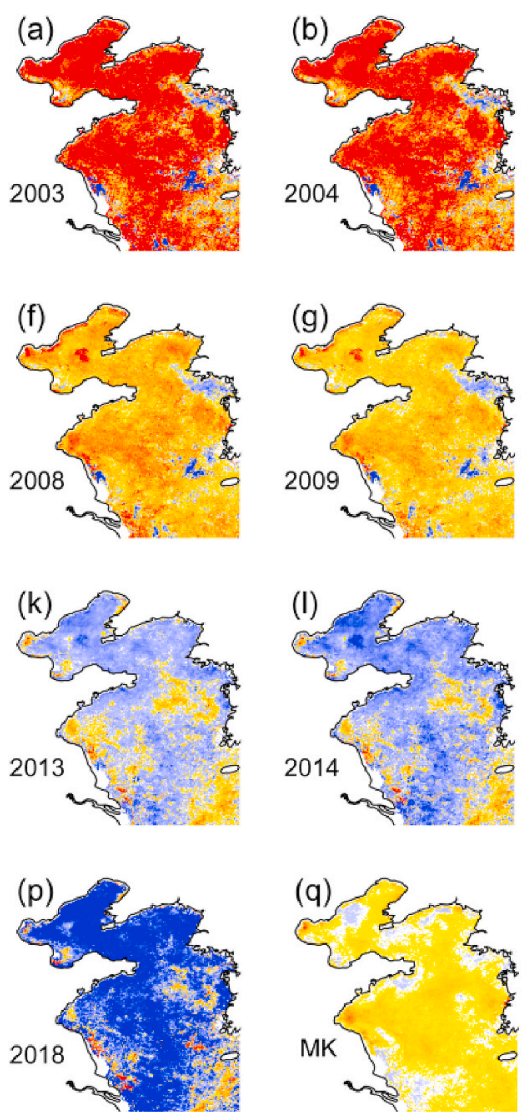
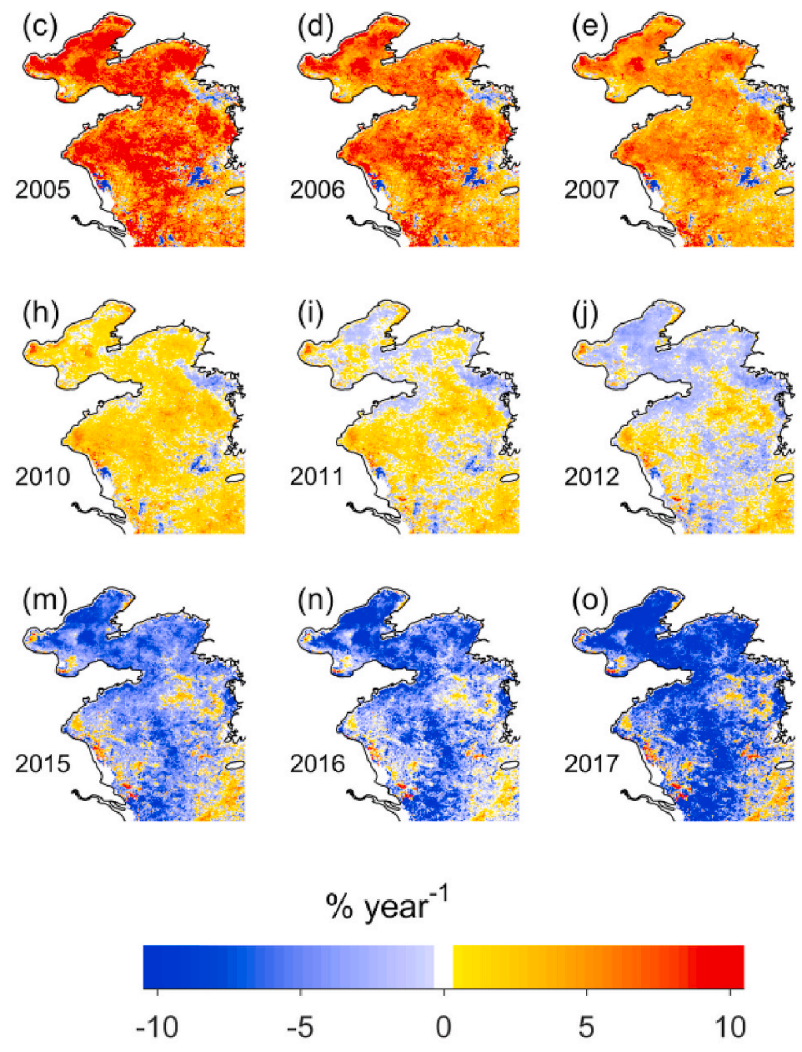

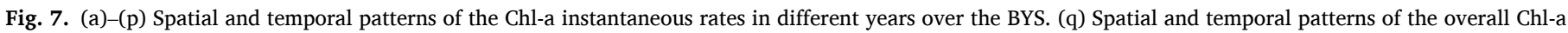
relative rates based on the linear trend analysis for 2002-2018.

\subsection{Potential drivers of Chl-a trends}

To directly compare the evolution of Chl-a trend with the trends of the considered variables, all the time series of EEMD trends were normalised and plotted in Fig. 14. The consistency in trends between the environmental variables (i.e., nutrient, light and temperature) and Chl-a were analysed, and the interplay between them was discussed.

\subsubsection{Drivers for the overall positive Chl-a trend in the BYS}

From the linear trend analysis (obtained from MK test), an overall significant positive Chl-a trend was detected in the BYS during 2002-2018. This result is in agreement with previous studies, which also revealed positive Chl-a trends in the BYS or around its adjacent areas throughout similar periods (Kong et al., 2019; Liu et al., 2019; Xing et al., 2015; Zhang et al., 2017). The increased phytoplankton biomass in marginal seas was well documented and was likely related to enhanced coastal eutrophication (Boyce and Worm, 2015; Jickells, 1998; Marrari et al., 2016). In contrast, many previous studies have shown that the global phytoplankton biomass for open oceans has decreased over the last decades (Boyce et al., 2010; Gregg and Rousseaux, 2014; Signorini et al., 2015), which has been largely attributed to ocean warming possibly with direct and indirect effects (Lewandowska et al., 2014). For shallow marginal seas as the BYS, it is difficult to exactly interpret the drivers of Chl-a increase due to its complicated environmental conditions and multiple stressors (Kong et al., 2019; Wang et al., 2015). Here, we only try to explore the main direct variables (i.e. temperature, light and nutrients), which might result in the Chl-a increase. From the view of the overall linear trend, sea surface warming occurred concurrently with the Chl-a increase during 2002-2018, which implies no causality between SST and Chl-a changes due to the reverse variation that always found between them, regardless of a physically or biologically mediated effect of warming on marine phytoplankton biomass (Lewandowska et al., 2014). In terms of $I_{\mathrm{PAR}}$ changes, despite in significant weak magnitude, an overall positive trend of $I_{\mathrm{PAR}}$ was found in the BYS (Table 4), which indicates the same direction of trends in $I_{\mathrm{PAR}}$ and Chl-a during 2002-2018. However, it is difficult to determine whether the enhanced light availability drove the Chl-a increase during this period for two seasons: 1) the increase in $I_{\mathrm{PAR}}$ was not significant, while the Chl-a increase was significant; 2) the Chl-a increase mainly occurred during spring and summer (Table 2) when the light was generally not a limiting factor for phytoplankton growth in the BYS, whereas the $I_{\mathrm{PAR}}$ decreased in autumn and winter when the phytoplankton growth was strongly limited by light conditions. As a consequence, we suggest that the change in the light intensity in the water column was not the main driver for Chl-a increase during the study period. For nutrient enrichment, despite the lack of significance, the overall trend of NEI was positive from 2002 to 2018 . The increased nutrient would alleviate the nutrient limitation in phytoplankton growth, which particularly present in spring and summer, as indicated in Table 2. In summary, the nutrient was more likely than the temperature and light to driver the overall positive Chl-a trend in the BYS during 2002-2018.

\subsubsection{Drivers for seasonal difference of Chl-a linear trends in the BYS}

In the context of an overall positive trend, Chl-a also exhibited different linear trends across seasons (Table 2). That is, strong significant positive Chl-a trends were found from spring to summer, while no significant Chl-a increase was detected in autumn and winter. To interpret the underlining mechanisms behind them, the drivers of different Chl-a annual cycles should be clarified and compared. Although different Chl-a annual cycles may be found among the coastal and oceanic provinces, the universal nutrient limitation of 

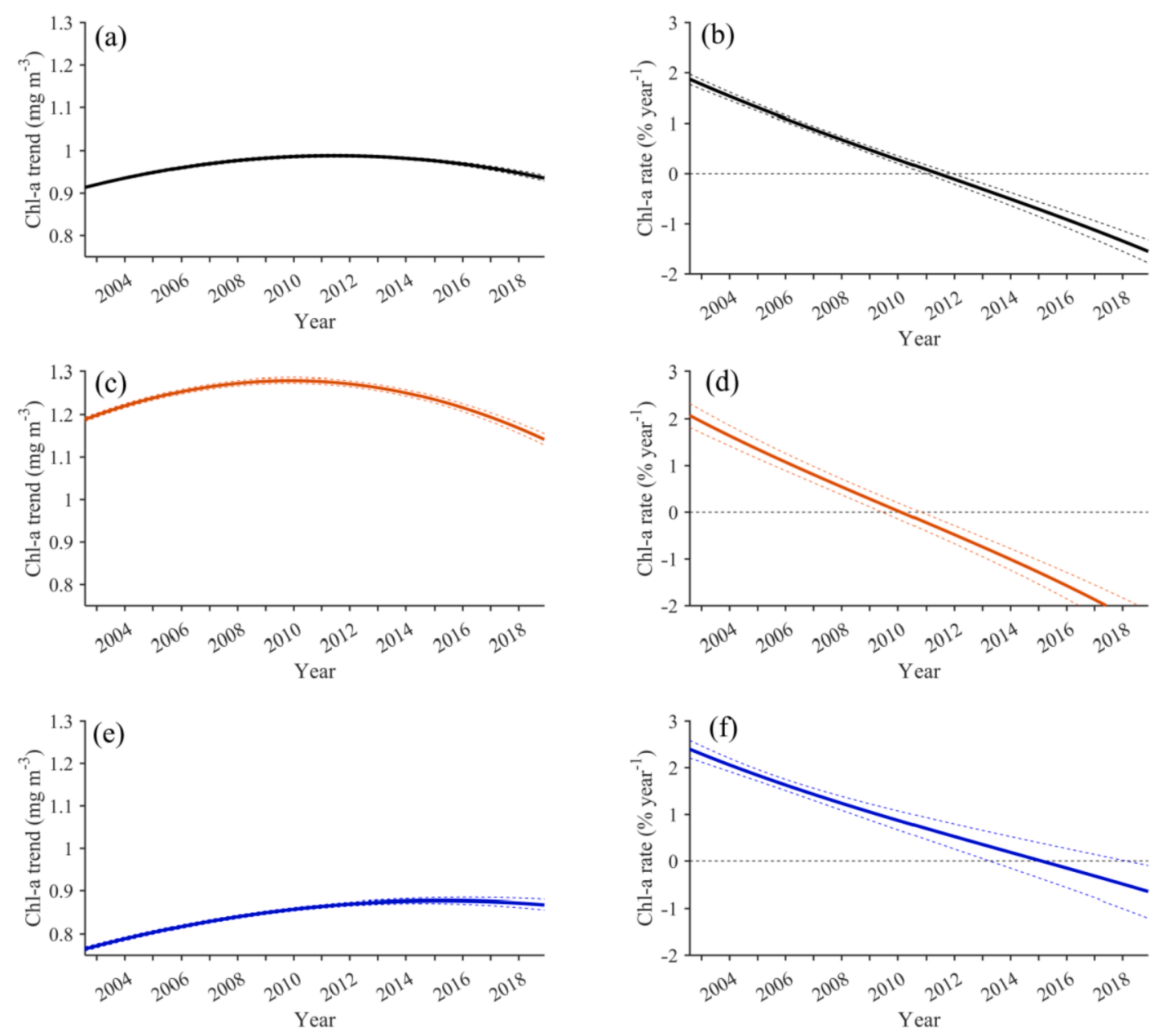

Fig. 8. Nonlinear trends of Chl-a for the three different regions. (a, c, and e) The EEMD trends and (b, d, and f) the corresponding instantaneous relative rates of Chl-a

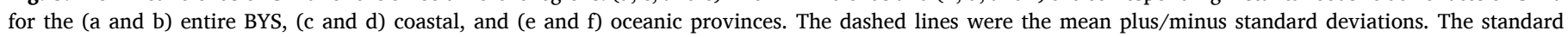
deviation was calculated from 200 iterations.

Table 3

Trends of SST in different seasons for the different regions.

\begin{tabular}{lllll}
\hline Season & SST mean $\left({ }^{\circ} \mathrm{C}\right)$ & $\begin{array}{l}\text { Slope } \\
\left({ }^{\circ} \mathrm{C} \text { Year }^{-1}\right)\end{array}$ & $\begin{array}{l}\text { Relative rate } \\
\left(\% \text { Year }^{-1}\right)\end{array}$ & $p$-value \\
\hline Overall & 15.68 & 0.027 & 0.17 & 0.19 \\
Spring & 9.96 & 0.041 & 0.40 & 0.32 \\
Summer & 23.45 & 0.058 & 0.23 & 0.15 \\
Autumn & 20.47 & 0.006 & 0.03 & 0.74 \\
Winter & 8.33 & 0.037 & 0.42 & 0.96 \\
Overall & 15.00 & 0.028 & 0.19 & 0.26 \\
Spring & 9.40 & 0.053 & 0.54 & 0.21 \\
Summer & 23.44 & 0.052 & 0.21 & 0.18 \\
Autumn & 20.22 & 0.009 & 0.04 & 0.93 \\
Winter & 6.48 & 0.032 & 0.47 & 0.93 \\
Overall & 16.13 & 0.030 & 0.19 & 0.15 \\
Spring & 10.41 & 0.035 & 0.32 & 0.65 \\
Summer & 23.45 & 0.066 & 0.27 & 0.13 \\
Autumn & 20.66 & 0.008 & 0.04 & 0.51 \\
Winter & 9.78 & 0.050 & 0.49 & 0.72 \\
\hline
\end{tabular}

Note: No significant linear trend was found.

phytoplankton biomass coincided from late spring to early autumn over most of the BYS, while the light limitation of phytoplankton growth mainly presented in winter throughout the BYS (Hao et al., 2019; Jin et al., 2013; Zhang et al., 2017). As a consequence of nutrient increase, the nutrient limitation of phytoplankton might be gradually released in spring and summer due to the aggravation of eutrophication over the last decades (Lee et al., 2019; Strokal et al., 2014; Wang et al., 2015,
2018; Yang et al., 2018). Therefore, the significant increase in nutrient supply is associated with no significant changes in light availability and SST contributes to an overall increasing trend of Chl-a concentration in spring and summer. However, in winter, the phytoplankton growth was generally controlled by light limitation (Fu et al., 2009; Hao et al., 2019; Zhang et al., 2017), although the level of nutrients might also increase as in other seasons, no significant Chl-a trend was detected because the light condition was not significantly changed (Table 4).

\subsubsection{Drivers for Chl-a trends shift from upwards to downwards}

The EEMD spatiotemporal analysis showed that the Chl-a trends in the BYS during 2002-2018, in most cases, were highly nonlinear and varied over time. Therefore, the assumption of linear trends, what many previous studies were based on, may be arbitrary and insufficient to capture the evolutionary features and the drivers of the Chl-a trends. The instantaneous rate of Chl-a change in the BYS continuously decreased from nearly $2 \%$ year $^{-1}$ in 2002 to approximately $-2 \%$ year $^{-1}$ in 2018 , in contrast to an overall positive linear trend of approximately $1.15 \%$ year $^{-1}$ from the MK analysis. The decreasing rate resulted in a prominent turning point in the Chl-a trends, which indicates a shift of the Chl-a trend from positive to negative. In fact, some previous reports have mentioned that the turning of Chl-a trends from an increase to a decrease in recent years (Kong et al., 2019; Zhai et al., 2021). However, this phenomenon has not been of great concern because of the different aims of the studies and the relatively short time span of data obtained after 2010. With the ongoing accumulation of remote sensing Chl-a data, the 


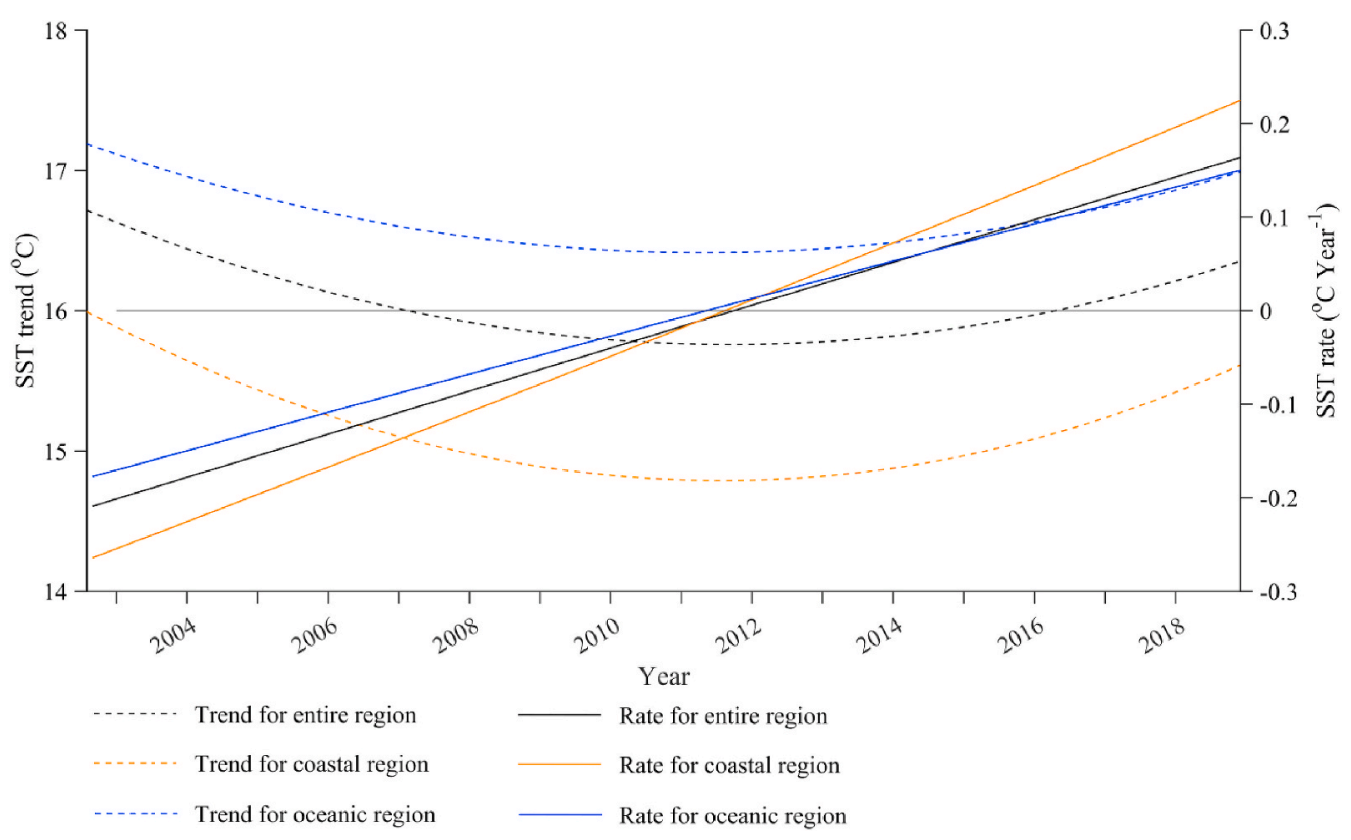

Fig. 9. Nonlinear trends and the corresponding instantaneous rates of averaged SST in different regions.

Table 4

Trends of $I_{\mathrm{PAR}}$ in different seasons for the different regions.

\begin{tabular}{lllll}
\hline Season & $\begin{array}{l}I_{\text {PAR mean }} \\
\left(\mu \mathrm{m} \text { photons } \mathrm{m}^{-2}\right. \\
\left.\mathrm{s}^{-1}\right)\end{array}$ & $\begin{array}{l}\text { Slope } \\
\left(\mu \mathrm{m}_{\text {photons } \mathrm{m}^{-2}}\right.\end{array}$ & $\begin{array}{l}\text { Relative } \\
\text { rate } \\
\left(\% \mathrm{Year}^{-1}\right)\end{array}$ & $\begin{array}{l}p \text { - } \\
\text { value }\end{array}$ \\
\hline Overall & 176.31 & 0.017 & 0.01 & 0.64 \\
Spring & 197.75 & -0.329 & -0.17 & 0.79 \\
Summer & 248.01 & 1.029 & 0.41 & 0.05 \\
Autumn & 148.06 & -0.343 & -0.23 & 0.62 \\
Winter & 92.55 & -0.150 & -0.17 & 0.96 \\
Overall & 153.54 & 0.130 & 0.08 & 0.64 \\
Spring & 173.88 & 0.322 & 0.19 & 0.53 \\
Summer & 197.13 & 0.619 & 0.31 & 0.05 \\
Autumn & 122.92 & -0.193 & -0.16 & 0.80 \\
Winter & 84.55 & -0.100 & -0.11 & 0.72 \\
Overall & 185.61 & -0.028 & -0.02 & 0.77 \\
Spring & 212.25 & -0.566 & -0.27 & 0.59 \\
Summer & 284.79 & 1.152 & 0.40 & 0.07 \\
Autumn & 167.78 & -0.670 & -0.40 & 0.51 \\
Winter & 99.20 & -0.300 & -0.30 & 0.79 \\
\hline
\end{tabular}

Note: No significant linear trend was found.

nonlinear evolutionary feature of the Chl-a trend during the last decade should be given more attention and be well addressed, as we did in this study. In addition, other studies have investigated evolution of the satellite-derived Chl-a trends for other specific regions, which also obtained a prominent non-monotonic nature of local Chl-a changes (Jo et al., 2016; Zhang et al., 2018).

The appearance of the trend shift was also mainly attributed to the changes in nutrient enrichment, due to the strong positive correlation (correlation coefficient is 0.96 ) and the best coincidence between the Chl-a and NEI trends. Previous reports have shown that the coastal eutrophication situation was rapidly aggravated from the end of the 1980s to the mid-2000s, after which the trend has been curbed (Wang et al., 2018), which may have resulted in decreased nutrient levels. This change in nutrient status was also confirmed in our study. The nutrient enrichment of the BYS presented a significant upward trend from 2002 to 2012 and a significant downwards trend after that, which nearly coincides with the evolution of the Chl-a trend. In addition, a clear delay in turning date was observed in the oceanic province compared with the coastal province (Fig. 8), which was probably due to the different response speeds to the improvement of eutrophication status between them. In coastal provinces, the proximity to terrestrial nutrient sources (Fig. 1a) associated with the long retention time of the sea water contributes to the high response speed to variation of in nutrient input (Guan, 1994; Wei et al., 2004). In contrast, the oceanic provinces are far from terrestrial nutrient sources and preserve greater weight of the local nutrient supply such as sediment resuspension (Li et al., 2013; Wang et al., 2003), which results in lower response speed and less sensitivity to changes in terrestrial nutrient inputs. In addition, the oceanic province generally has higher degree of nutrient limitation than the coastal province due to its relatively lower nutrient levels and higher light intensity in the water column. As a consequence, the turning date of Chl-a trend for the oceanic province was later than that for the coastal province.

In the long-term scale, SST and Chl-a generally present a reverse trend due to the negative effect of SST on the standing stock of Chl-a (Boyce and Worm, 2015; Lewandowska et al., 2014). In our study, SST of the BYS was decline from 2002 to 2011, which probably reinforce the Chl-a increase. On one hand, the decreased SST enables an increase in nutrient supply by weakening the stratification and enhancing the water mixing. However, the decreased SST enables the reduction of grazing pressure by inhibiting the grazer biomass (Rose and Caron, 2007). On the contrary, after 2011, the SST gradually increased, which probably reinforced the Chl-a decrease.

Although no significant linear trend was found in the $I_{\mathrm{PAR}}$, a clear nonlinear trend with the $I_{\mathrm{PAR}}$ turned from the initial slight decrease to the rapid increase was delineated over 2002-2018. It is difficult to directly interpret the contribution of light changes to Chl-a changes. However, a prominent phenomenon showed that the Chl-a decline after 2011 coincided with an increase in light (correlation coefficient is -0.69 ), then, which enabled us to conclude that the Chl-a decline from 2012 to 2018 was likely not related to light availability. In fact, $I_{\mathrm{PAR}}$ could act as a direct driver or an outcome of the changes in phytoplankton biomass in the water column (Kirk, 1994). When the change in $I_{\mathrm{PAR}}$ acts as a driver, Chl-a is expected to increase with enhanced $I_{\mathrm{PAR}}$, resulting in the same trend direction of trends. However, an enhanced $I_{\mathrm{PAR}}$ could also be a result of the decreased Chl-a due to the reduced absorption of PAR from phytoplankton decline (Kirk, 1994). In the BYS, apparent reversed changes were delineated between the light and Chl-a nonlinear trends from EEMD analysis (Fig. 14), which suggests that the light is more likely a result rather than a driver of Chl-a change in this 


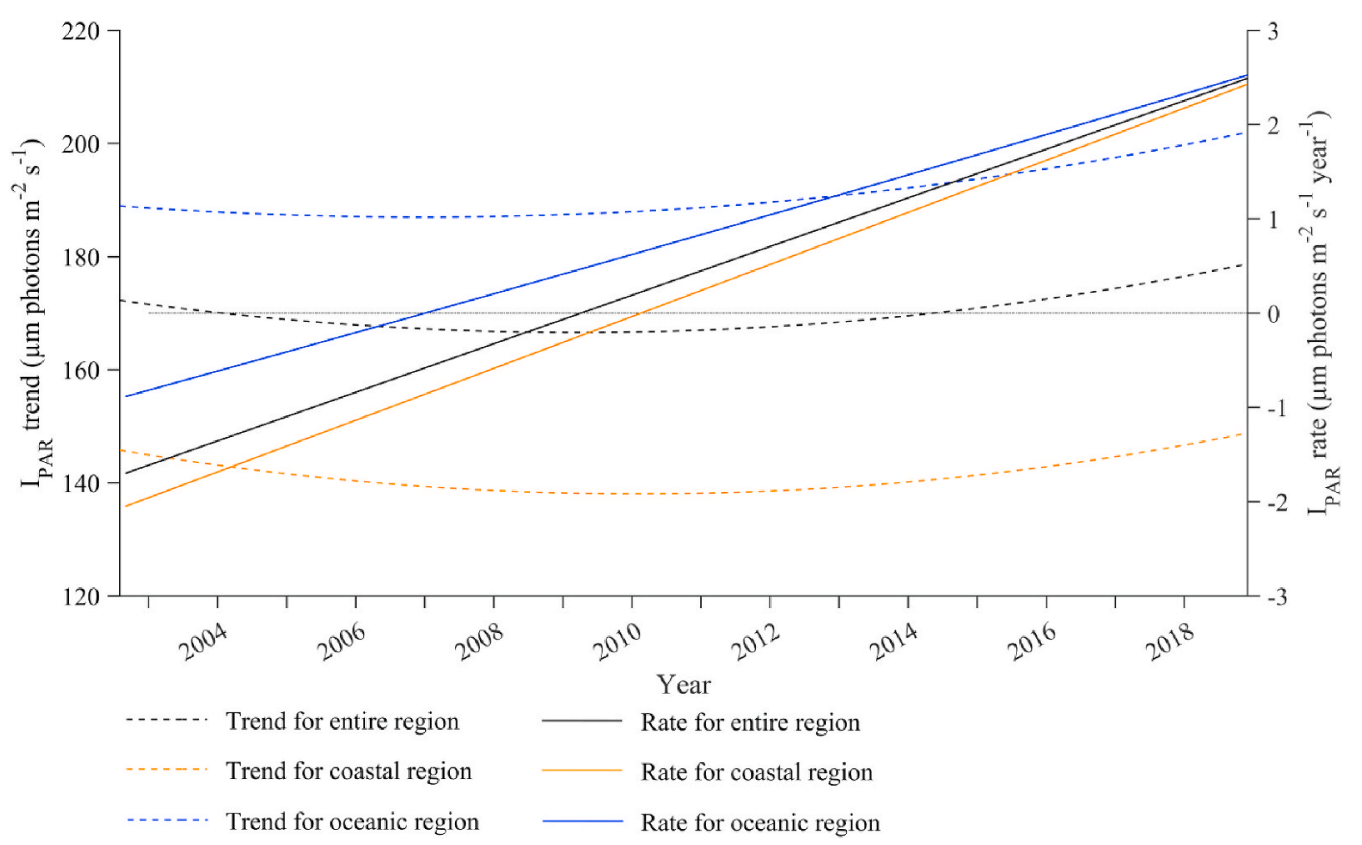

Fig. 10. Nonlinear trends and the corresponding instantaneous rates of averaged IPAR for different regions.
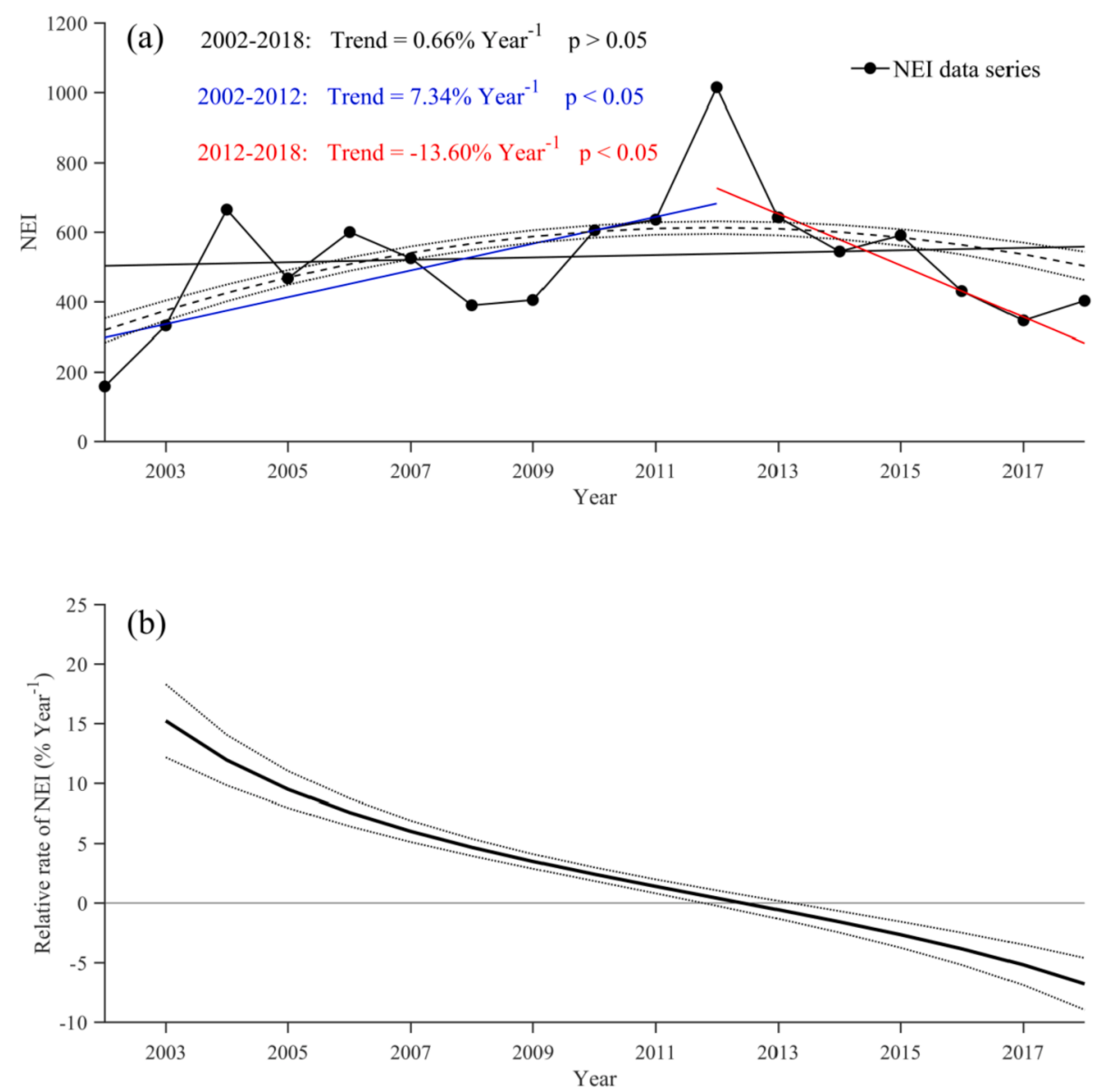

Fig. 11. Linear and nonlinear trends of NEI in the BYS. (a) Variation of NEI and the corresponding linear and nonlinear trends over different periods. (b) Instantaneous relative rate for the nonlinear trend of NEI. The dashed lines were the mean plus/minus standard deviations obtained from 200 iterations. 

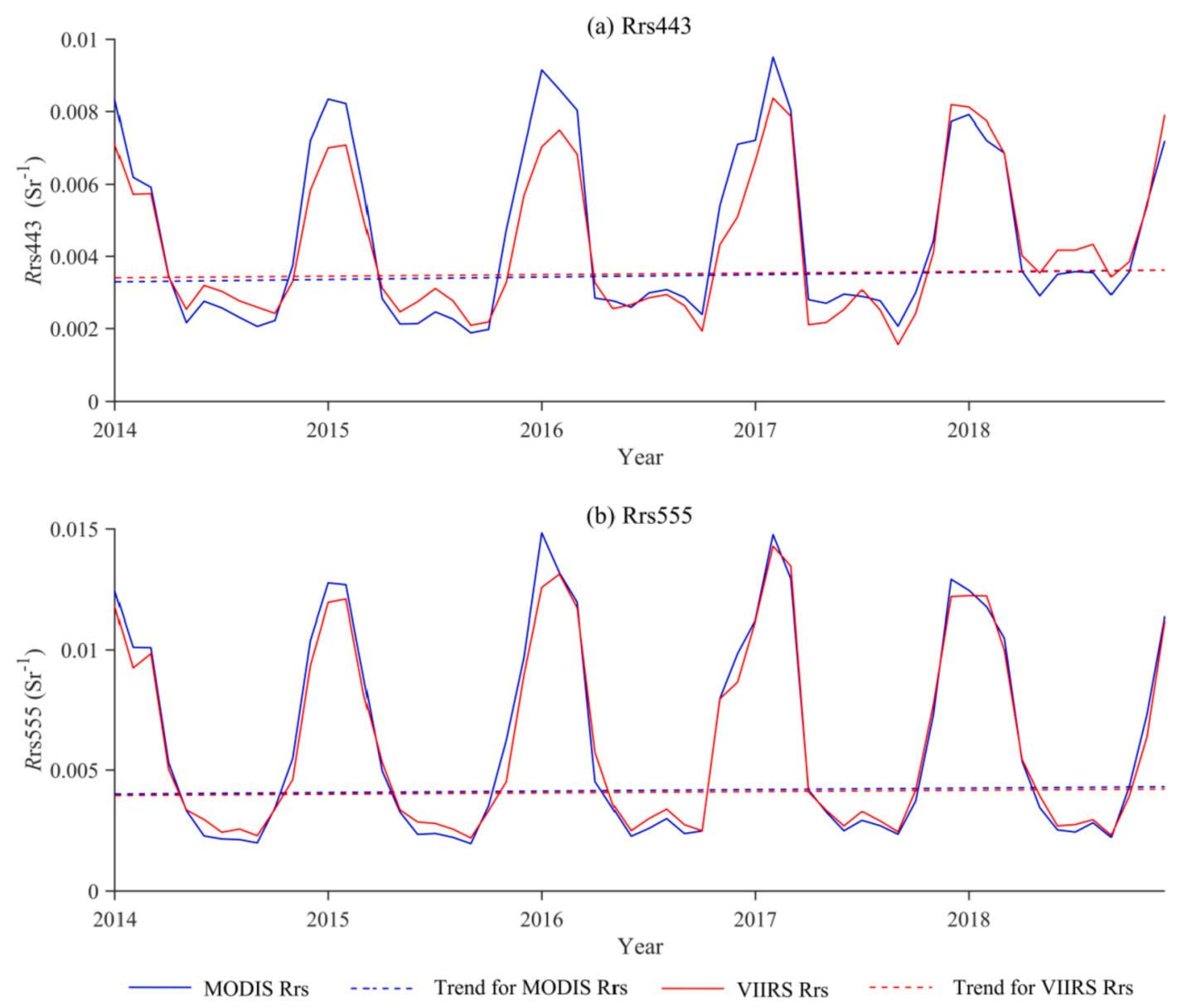

Fig. 12. Time series of the basin-averaged $R_{\mathrm{rs}}$ at (a) $443 \mathrm{~nm}$ and (b) $555 \mathrm{~nm}$ for MODIS and VIIRS.

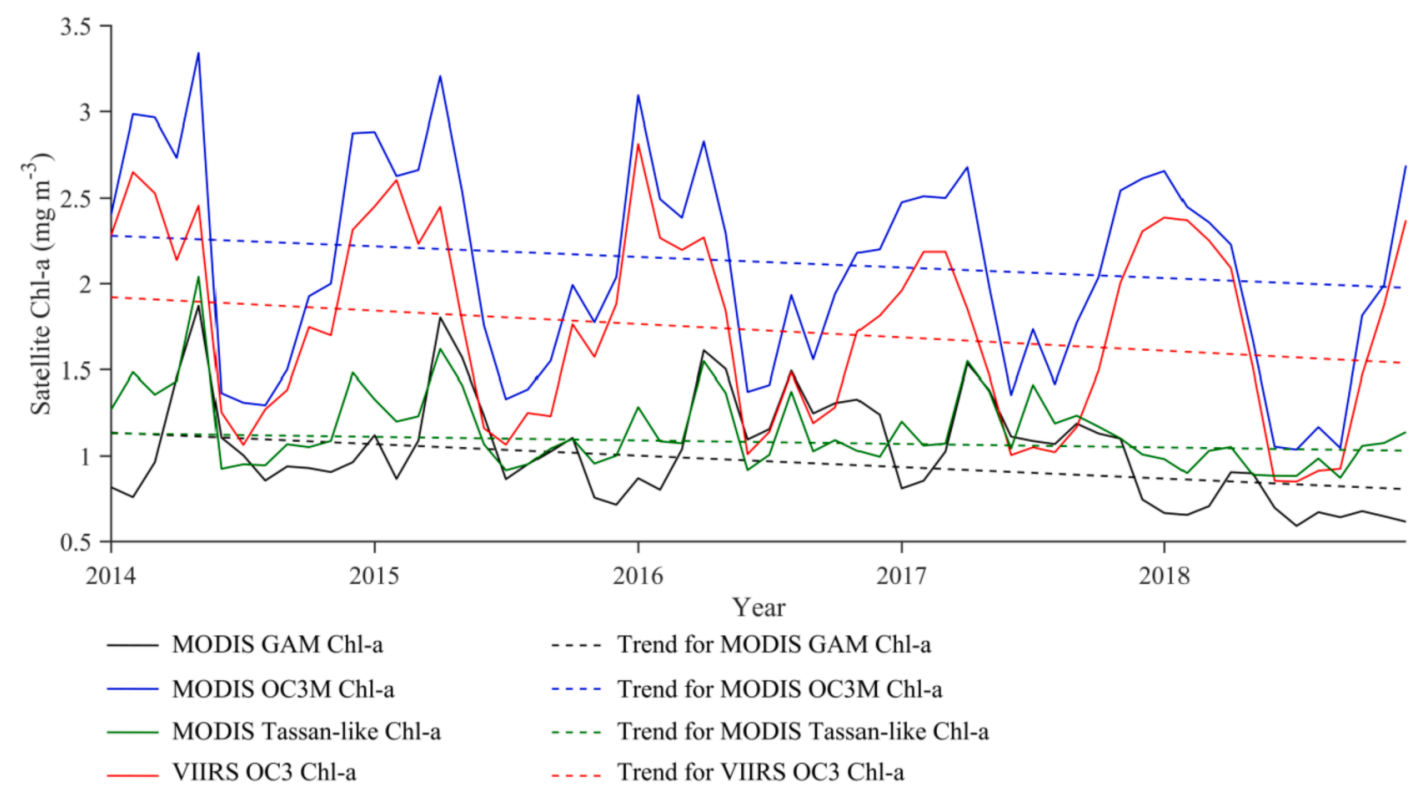

Fig. 13. Time series and the corresponding trends for the basin-averaged Chl-a derived from the different algorithms.

area.

\section{Conclusion}

This study presents, to our knowledge, the first comparative analysis of linear and nonlinear Chl-a trends in the BYS during 2002-2018. The linear trend obtained by MK test showed an overall positive Chl-a trend $\left(\sim 1.15 \%\right.$ year $\left.^{-1}\right)$ with prominent spatial heterogeneity and seasonal difference. Chl-a had a larger increase in spring and summer, while a lower increase and even negative trend was found in autumn and winter. 


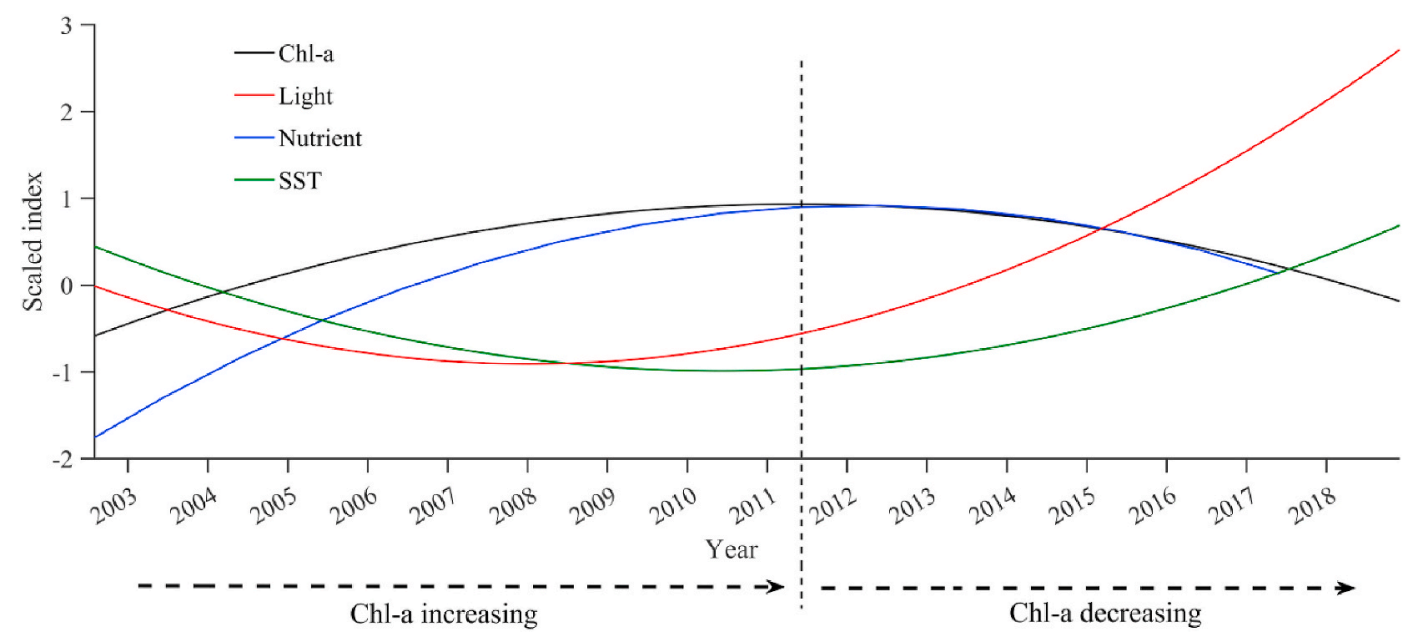

Fig. 14. The nonlinear trend of Chl-a overlap with the nonlinear trends of light, nutrient and SST for the entire BYS.

Limiting factors of phytoplankton growth in different seasons associated with the overall nutrient increase contribute to the seasonal difference in Chl-a trends. The EEMD analysis revealed highly nonlinear Chl-a trends and time-varying rates over the BYS, with a gradual increase in Chl-a since 2002 (with a rate of $+2.0 \%$ year $^{-1}$ ), then turned to Chl-a decline from 2011 to 2018 (reaching to $-2.0 \%$ year $^{-1}$ in 2018). Consequently, the commonly used linear trend might not capture the evolutionary features of Chl-a trends, because the direction and changing rate of the Chl-a trend may vary significantly with time. The best consistency between changes in nutrient status and Chl-a suggests that the nutrient level might be the main driver of Chl-a change by influencing the nutrient supply for phytoplankton growth in this area. In contrast, SST and light seem to impose limited impact on long-term Chl-a change. In this sense, the Chl-a concentration and its change might be efficient indicators of eutrophication status in the BYS.

\section{Declaration of competing interest}

The authors declare that they have no known competing financial interests or personal relationships that could have appeared to influence the work reported in this paper.

\section{Acknowledgements}

This work was supported by the National Natural Science Foundation of China [grant numbers 41706134, 42030402]; the Open Fund of CAS Key Laboratory of Marine Ecology and Environmental Sciences, Institute of Oceanology, Chinese Academy of Sciences [KLMEES202005]; the Shandong Province Natural Science Foundation, China [grant number E031031501]; the Key Deployment Project of Center for Ocean MegaScience, Chinese Academy of Sciences (COMS2019J02); the Key Research Program of Frontier Science, Chinese Academy of Sciences (ZDBS-LY-7010).

\section{References}

Bai, K., Chang, N.-B., Shi, R., Yu, H., Gao, W., 2017. An intercomparison of multidecadal observational and reanalysis data sets for global total ozone trends and variability analysis. J. Geophys. Res. Atmos. 122, 7119-7139.

Barnett, T.P., Pierce, D.W., Schnur, R., 2001. Detection of anthropogenic climate change in the World's oceans. Science 292, 270-274.

Basterretxea, G., Font-Muñoz, J.S., Salgado-Hernanz, P.M., Arrieta, J., HernándezCarrasco, I., 2018. Patterns of chlorophyll interannual variability in Mediterranean biogeographical regions. Rem. Sens. Environ. 215, 7-17.

Beaulieu, C., Henson, S.A., Sarmiento, J.L., Dunne, J.P., Doney, S.C., Rykaczewski, R.R., Bopp, L., 2013. Factors challenging our ability to detect long-term trends in ocean chlorophyll. Biogeosciences 10, 2711-2724.

Boyce, D.G., Dowd, M., Lewis, M.R., Worm, B., 2014. Estimating global chlorophyll changes over the past century. Prog. Oceanogr. 122, 163-173.
Boyce, D.G., Lewis, M.R., Worm, B., 2010. Global phytoplankton decline over the past century. Nature 466, 591-596.

Boyce, D.G., Worm, B., 2015. Patterns and ecological implications of historical marine phytoplankton change. Mar. Ecol. Prog. Ser. 534, 251-272.

Campbell, J.W., 1995. The lognormal distribution as a model for bio-optical variability in the sea. J. Geophys. Res. 100, 13237-13254.

Chen, C.T.A., 2009. Chemical and physical fronts in the Bohai, Yellow and East China seas. J. Mar. Syst. 78, 394-410.

Chen, J., Liu, J.L., 2015. The spatial and temporal changes of chlorophyll-a and suspended matter in the eastern coastal zones of China during 1997-2013. Continent. Shelf Res. 95, 89-98.

Colella, S., Falcini, F., Rinaldi, E., Sammartino, M., Santoleri, R., 2016. Mediterranean ocean colour chlorophyll trends. PLoS One 11, e0155756.

Cui, T., Zhang, J., Groom, S., Sun, L., Smyth, T., Sathyendranath, S., 2010. Validation of MERIS ocean-color products in the Bohai Sea: a case study for turbid coastal waters. Rem. Sens. Environ. 114, 2326-2336.

Demarcq, H., Reygondeau, G., Alvain, S., Vantrepotte, V., 2012. Monitoring marine phytoplankton seasonality from space. Rem. Sens. Environ. 117, 211-222.

Doney, S.C., Glover, D.M., McCue, S.J., Fuentes, M., 2003. Mesoscale variability of Seaviewing Wide Field-of-view Sensor(SeaWiFS) satellite ocean color: global patterns and spatial scales. J. Geophys. Res. Oceans 108, 3024.

Falkowski, P.G., Raven, J.A., 2007. Aquatic Photosynthesis, second ed. Princeton University Press, Princeton.

Feng, J.F., Zhu, L., 2012. Changing trends and relationship between global ocean chlorophyll and sea surface temperature. Procedia Environ. Sci. 13, 626-631.

Field, C.B., Behrenfeld, M.J., Randerson, J.T., Falkowski, P., 1998. Primary production of the biosphere: integrating terrestrial and oceanic components. Science 281, 237-240.

Friedland, K.D., Mouw, C.B., Asch, R.G., Ferreira, A.S.A., Henson, S., Hyde, K.J.W., Morse, R.E., Thomas, A.C., Brady, D.C., 2018. Phenology and time series trends of the dominant seasonal phytoplankton bloom across global scales. Global Ecol. Biogeogr. 27, 551-569.

Frouin, R., 2003. The SeaWiFS PAR product. In: Hooker, S.B., Firestone, E.R. (Eds.), Algorithm Updates for the Fourth SeaWiFS Data Reprocessing, pp. 45-50.

Fu, M., Wang, Z., Li, Y., Li, R., Sun, P., Wei, X., Lin, X., Guo, J., 2009. Phytoplankton biomass size structure and its regulation in the Southern Yellow Sea (China): seasonal variability. Continent. Shelf Res. 29, 2178-2194.

Fu, Y., Xu, S., Liu, J., 2016. Temporal-spatial variations and developing trends of chlorophyll-a in the Bohai Sea, China. Estuarine. Coastal Shelf Sci. 173, 49-56.

Gilbert, R.O., 1987. Statistical Methods for Environmental Pollution Monitoring.

Gregg, W.W., Casey, N.W., McClain, C.R., 2005. Recent trends in global ocean chlorophyll. Geophys. Res. Lett. 32, L03606.

Gregg, W.W., Casey, N.W., O'Reilly, J.E., Esaias, W.E., 2009. An empirical approach to ocean color data: reducing bias and the need for post-launch radiometric recalibration. Rem. Sens. Environ. 113, 1598-1612.

Gregg, W.W., Rousseaux, C.S., 2014. Decadal trends in global pelagic ocean chlorophyll: a new assessment integrating multiple satellites, in situ data, and models. J. Geophys. Res. Oceans 119, 5921-5933.

Gregg, W.W., Rousseaux, C.S., Franz, B.A., 2017. Global trends in ocean phytoplankton: a new assessment using revised ocean colour data. Rem. Sens. Lett. 8, 1102-1111.

Guan, B., 1994. Patterns and structures of the currents in Bohai, Huanghai and East China sea. In: Zhou, D., Liang, Y., Tseng, C. (Eds.), Oceanology of China Sea. Kluwer Academic Publishers, Netherlands, pp. 17-26.

Hammond, M.L., Beaulieu, C., Henson, S.A., Sahu, S.K., 2018. Assessing the presence of discontinuities in the ocean color satellite record and their effects on chlorophyll trends and their uncertainties. Geophys. Res. Lett. 45, 7654-7662.

Hammond, M.L., Beaulieu, C., Sahu, S.K., Henson, S.A., 2017. Assessing trends and uncertainties in satellite-era ocean chlorophyll using space-time modeling. Global Biogeochem. Cycles 31, 1103-1117. 
Hao, Q., Chai, F., Xiu, P., Bai, Y., Chen, J.F., Liu, C.G., Le, F.F., Zhou, F., 2019. Spatial and temporal variation in chlorophyll a concentration in the Eastern China Seas based on a locally modified satellite dataset. Estuar. Coast Shelf Sci. 220, 220-231.

Henson, S.A., Cole, H.S., Hopkins, J., Martin, A.P., Yool, A., 2018. Detection of climate change-driven trends in phytoplankton phenology. Global Change Biol. 24, e101-e111.

Hirsch, R.M., Slack, J.R., 1984. A nonparametric trend test for seasonal data with serial dependence. Water Resour. Res. 20, 727-732.

Hirsch, R.M., Slack, J.R., Smith, R.A., 1982. Techniques of trend analysis for monthly water quality data. Water Resour. Res. 18, 107-121.

Hoegh-Guldberg, O., Bruno, J.F., 2010. The impact of climate change on the World's marine ecosystems. Science 328, 1523-1528.

Hu, S., Fedorov, A.V., 2017. The extreme El Niño of 2015-2016 and the end of global warming hiatus. Geophys. Res. Lett. 44, 3816-3824.

IOCCG, 2000. Remote sensing of ocean colour in coastal and other optically complex waters,reports of the International Ocean-Colour Coordination Group, no. 3. In: Sathyendranath, S. (Ed.), Reports of the International Ocean Color Coordinating Group, Dartmouth, Canada, p. 140.

Ji, F., Wu, Z.H., Huang, J.P., Chassignet, E.P., 2014. Evolution of land surface air temperature trend. Nat. Clim. Change 4, 462-466.

Jickells, T., 1998. Nutrient biogeochemistry of the coastal zone. Science 281, 217-222.

Jin, J., Liu, S.M., Ren, J.L., Liu, C.G., Zhang, J., Zhang, G.L., Huang, D.J., 2013. Nutrient dynamics and coupling with phytoplankton species composition during the spring blooms in the Yellow Sea. Deep Sea Res. Part II Top. Stud. Oceanogr. 97, 16-32.

Jo, Y.-H., Kim, H.-C., Son, S., Kim, D., 2016. Analysis of the timing of phase changes in the chlorophyll concentration in the East/Japan Sea. Continent. Shelf Res. 127, $1-11$.

Joint, I., Groom, S.B., 2000. Estimation of phytoplankton production from space: current status and future potential of satellite remote sensing. J. Exp. Mar. Biol. Ecol. 250, 233-255.

Kahru, M., Kudela, R., Manzano-Sarabia, M., Mitchell, B.G., 2009. Trends in primary production in the California Current detected with satellite data. J. Geophys. Res. 114, C02004.

Kim, H.-C., Son, S., Kim, Y.H., Khim, J.S., Nam, J., Chang, W.K., Lee, J.-H., Lee, C.-H., Ryu, J., 2007. Remote sensing and water quality indicators in the Korean West coast: spatio-temporal structures of MODIS-derived chlorophyll-a and total suspended solids. Mar. Pollut. Bull. 121, 425-434.

Kirk, J.T., 1994. Light and Photosynthesis in Aquatic Ecosystems. Cambridge university press.

Kong, C.E., Yoo, S., Jang, C.J., 2019. East China Sea ecosystem under multiple stressors: heterogeneous responses in the sea surface chlorophyll-a. Deep-Sea Res. Part I Oceanogr. Res. Pap. 151, 103078.

Kosaka, Y., Xie, S.-P., 2013. Recent global-warming hiatus tied to equatorial Pacific surface cooling. Nature 501, 403-407.

Krug, L.A., Platt, T., Sathyendranath, S., Barbosa, A.B., 2017. Unravelling region-specific environmental drivers of phytoplankton across a complex marine domain (off SW Iberia). Rem. Sens. Environ. 203, 162-184.

Lamont, T., Barlow, R.G., Brewin, R.J.W., 2019. Long-term trends in phytoplankton chlorophyll a and size structure in the Benguela upwelling system. J. Geophys. Res. Oceans 124, 1170-1195.

Lee, K.H., Jeong, H.J., Lee, K., Franks, P.J.S., Seong, K.A., Lee, S.Y., Lee, M.J., Hyeon Jang, S., Potvin, E., Suk Lim, A., Yoon, E.Y., Yoo, Y.D., Kang, N.S., Kim, K.Y., 2019. Effects of warming and eutrophication on coastal phytoplankton production. Harmful Algae 81, 106-118.

Lewandowska, A.M., Boyce, D.G., Hofmann, M., Matthiessen, B., Sommer, U., Worm, B. 2014. Effects of sea surface warming on marine plankton. Ecol. Lett. 17, 614-623.

Li, Y., Hu, Y., Chen, S., 2013. Distribution and influence factors of nutrients in the North Yellow Sea in summer and autumn (in Chinese with English abstract). China Environ. Sci. 33, 1060-1067.

Li, Y., Ren, G., Wang, Q., You, Q., 2019. More extreme marine heatwaves in the China Seas during the global warming hiatus. Environ. Res. Lett. 14, 104010.

Lie, H.J., Cho, C.H., Lee, S., 2009. Tongue-shaped frontal structure and warm water intrusion in the southern Yellow Sea in winter. J. Geophys. Res. Oceans 114, C01003.

Liu, C., Sun, Q., Xing, Q., Wang, S., Tang, D., Zhu, D., Xing, X., 2019. Variability in phytoplankton biomass and effects of sea surface temperature based on satellite data from the Yellow Sea, China. PLoS One 14, e0220058.

Liu, D.Y., Wang, Y.Q., 2013. Trends of satellite derived chlorophyll-a (1997-2011) in the Bohai and Yellow Seas, China: effects of bathymetry on seasonal and inter-annual patterns. Prog. Oceanogr. 116, 154-166.

Liu, X., Huang, B., Huang, Q., Wang, L., Ni, X., Tang, Q., Sun, S., Wei, H., Liu, S., Li, C., Sun, J., 2015. Seasonal phytoplankton response to physical processes in the southern Yellow Sea. J. Sea Res. 95, 45-55.

Lorenzen, C.J., 1967. Determination of chlorophyll and pheopigments: spectrophotometric equations. Limnol. Oceanogr. 12, 343-346.

Marrari, M., Piola, A.R., Valla, D., Wilding, J.G., 2016. Trends and variability in extended ocean color time series in the main reproductive area of the Argentine hake, Merluccius hubbsi (Southwestern Atlantic Ocean). Rem. Sens. Environ. 177, 1-12.

Mask, A.C., O’Brien, J.J., Preller, R., 1998. Wind-driven effects on the Yellow Sea warm current. J. Geophys. Res. Oceans 103, 30713-30729.

Meister, G., Franz, B.A., 2014. Corrections to the MODIS Aqua calibration derived from MODIS Aqua ocean color products. IEEE Trans. Geosci. Rem. Sens. 52, 6534-6541.

Meister, G., Franz, B.A., Kwiatkowska, E.J., McClain, C.R., 2012. Corrections to the calibration of MODIS Aqua ocean color bands derived from SeaWiFS data. IEEE Trans. Geosci. Rem. Sens. 50, 310-319.
Melin, F., Vantrepotte, V., Chuprin, A., Grant, M., Jackson, T., Sathyendranath, S., 2017. Assessing the fitness-for-purpose of satellite multi-mission ocean color climate data records: a protocol applied to OC-CCI chlorophyll-a data. Rem. Sens. Environ. 203, $139-151$.

Melin, F., Zibordi, G., Berthon, J.F., 2007. Assessment of satellite ocean color products at a coastal site. Rem. Sens. Environ. 110, 192-215.

Nieto, K., Mélin, F., 2017. Variability of chlorophyll-a concentration in the Gulf of Guinea and its relation to physical oceanographic variables. Prog. Oceanogr. 151, 97-115.

O'Reilly, J.E., Maritorena, S., Mitchell, B.G., Siegel, D.A., Carder, K.L., Garver, S.A., Kahru, M., McClain, C., 1998. Ocean color chlorophyll algorithms for SeaWiFS. J. Geophys. Res. Oceans 103, 24937-24953.

Odermatt, D., Gitelson, A., Brando, V.E., Schaepman, M., 2012. Review of constituent retrieval in optically deep and complex waters from satellite imagery. Rem. Sens. Environ. 118, 116-126.

Park, K.A., Lee, E.Y., Chang, E., Hong, S.V., 2015. Spatial and temporal variability of sea surface temperature and warming trends in the Yellow Sea. J. Mar. Syst. 143, 24-38.

Reynolds, R.W., Smith, T.M., 1994. Improved global sea-surface temperature analyses using Optimum interpolation. J. Clim. 7, 929-948.

Reynolds, R.W., Smith, T.M., Liu, C., Chelton, D.B., Casey, K.S., Schlax, M.G., 2007. Daily high-resolution-blended analyses for sea surface temperature. J. Clim. 20, 5473-5496.

Rose, J.M., Caron, D.A., 2007. Does low temperature constrain the growth rates of heterotrophic protists? Evidence and implications for algal blooms in cold waters. Limnol. Oceanogr. 52, 886-895.

Rykaczewski, R.R., Dunne, J.P., 2011. A measured look at ocean chlorophyll trends. Nature 472, E5.

Sasai, Y., Richards, K.J., Ishida, A., Sasaki, H., 2012. Spatial and temporal variabilities of the chlorophyll distribution in the northeastern tropical Pacific: the impact of physical processes on seasonal and interannual time scales. J. Mar. Syst. 96-97, 24-31.

Sathyendranath, S., Brewin, R.J.W., Jackson, T., Mélin, F., Platt, T., 2017. Ocean-colour products for climate-change studies: what are their ideal characteristics? Rem. Sens. Environ. 203, 125-138.

Saulquin, B., Fablet, R., Mangin, A., Mercier, G., Antoine, D., Fanton d'Andon, O., 2013. Detection of linear trends in multi-sensor time series in presence of auto-correlated noise: application to the chlorophyll-a SeaWiFS and MERIS datasets and extrapolation to the incoming Sentinel 3 - OLCI mission. J. Geophys. Res. Oceans $118,3752-3763$.

Sen, P.K., 1968. Estimates of the regression coefficient based on Kendall's Tau. J. Am. Stat. Assoc. 63, 1379-1389.

Shi, J., Liu, Y., Mao, X., Guo, X., Wei, H., Gao, H., 2017. Interannual variation of spring phytoplankton bloom and response to turbulent energy generated by atmospheric forcing in the central Southern Yellow Sea of China: satellite observations and numerical model study. Continent. Shelf Res. 143, 257-270.

Shi, W., Wang, M.H., 2012. Satellite views of the Bohai Sea, Yellow Sea, and East China sea. Prog. Oceanogr. 104, 30-45.

Siegel, D.A., Behrenfeld, M.J., Maritorena, S., McClain, C.R., Antoine, D., Bailey, S.W., Bontempi, P.S., Boss, E.S., Dierssen, H.M., Doney, S.C., Eplee Jr., R.E., Evans, R.H., Feldman, G.C., Fields, E., Franz, B.A., Kuring, N.A., Mengelt, C., Nelson, N.B., Patt, F. S., Robinson, W.D., Sarmiento, J.L., Swan, C.M., Werdell, P.J., Westberry, T.K., Wilding, J.G., Yoder, J.A., 2013. Regional to global assessments of phytoplankton dynamics from the SeaWiFS mission. Rem. Sens. Environ. 135, 77-91.

Signorini, S.R., Franz, B.A., McClain, C.R., 2015. Chlorophyll variability in the oligotrophic gyres: mechanisms, seasonality and trends. Front. Mar. Sci. 2.

Siswanto, E., Tang, J., Yamaguchi, H., Ahn, Y.-H., Ishizaka, J., Yoo, S., Kim, S.-W., Kiyomoto, Y., Yamada, K., Chiang, C., Kawamura, H., 2011. Empirical ocean-color algorithms to retrieve chlorophyll-a , total suspended matter, and colored dissolved organic matter absorption coefficient in the Yellow and East China Seas. J. Oceanogr. 67, 627-650.

Smetacek, V., Cleorn, J.E., 2008. On phytoplankton trends. Science 319, 1346-1348.

Son, S., Wang, M., 2015. Diffuse attenuation coefficient of the photosynthetically available radiation Kd (PAR) for global open ocean and coastal waters. Rem. Sens. Environ. 159, 250-258.

Sravanthi, N., Ali, P.Y., Narayana, A.C., 2017. Merging gauge data and models with satellite data from multiple sources to aid the understanding of long-term trends in chlorophyll-a concentrations. Rem. Sens. Lett. 8, 419-428.

Strokal, M., Yang, H., Zhang, Y., Kroeze, C., Li, L., Luan, S., Wang, H., Yang, S., Zhang, Y., 2014. Increasing eutrophication in the coastal seas of China from 1970 to 2050. Mar. Pollut. Bull. 85, 123-140.

Sun, L., Guo, M., Wang, X., 2010. Ocean color products retrieval and validation around China coast with MODIS. Acta Oceanol. Sin. 29, 21-27.

Tan, S.C., Shi, G.Y., 2012. The relationship between satellite-derived primary production and vertical mixing and atmospheric inputs in the Yellow Sea cold water mass. Continent. Shelf Res. 48, 138-145.

Tang, Q.S., Ying, Y.P., Wu, Q., 2016. The biomass yields and management challenges for the Yellow sea large marine ecosystem. Environ. Dev. 17, 175-181.

Tollefson, J., 2014. Climate change: the case of the missing heat. Nature 505, 276-278.

Trenberth, K.E., Fasullo, J.T., 2013. An apparent hiatus in global warming? Earth's Future 1, 19-32.

Van Gelder, P.H.A.J.M., Mai, C.V., Wang, W., Shams, G., Rajabalinejad, M., Burgmeijer, M., 2008. Data management of extreme marine and coastal hydrometeorological events. J. Hydraul. Res. 46, 191-210.

Vantrepotte, V., Mélin, F., 2011. Inter-annual variations in the SeaWiFS global chlorophyll a concentration (1997-2007). Deep Sea Res. Oceanogr. Res. Pap. 58, 429-441. 
Wang, B., Wang, X., Zhan, R., 2003. Nutrient conditions in the Yellow Sea and the East China sea. Estuar. Coast Shelf Sci. 58, 127-136.

Wang, B., Xin, M., Wei, Q., Xie, L., 2018. A historical overview of coastal eutrophication in the China Seas. Mar. Pollut. Bull. 136, 394-400.

Wang, J., Yu, Z., Wei, Q., Yao, Q., 2019a. Long-term nutrient variations in the Bohai Sea over the past 40 years. J. Geophys. Res. Oceans 124, 703-722.

Wang, X.H., Cho, Y.-K., Guo, X., Wu, C.-R., Zhou, J., 2015. The status of coastal oceanography in heavily impacted Yellow and East China Sea: past trends, progress, and possible futures. Estuar. Coast Shelf Sci. 163, 235-243. Part B.

Wang, Y.Q., Gao, Z.Q., 2020. Contrasting chlorophyll-a seasonal patterns between nearshore and offshore waters in the Bohai and Yellow Seas, China: a new analysis using improved satellite data. Continent. Shelf Res. 203, 104173.

Wang, Y.Q., Gao, Z.Q., Liu, D.Y., 2019b. Multivariate DINEOF reconstruction for creating long-term cloud-free chlorophyll-a data records from SeaWiFS and MODIS: a case study in Bohai and Yellow seas, China. IEEE J. Sel. Top. Appl. Earth Observ. Rem. Sens. 12, 1383-1395.

Wang, Y.Q., Liu, D.Y., 2014. Reconstruction of satellite chlorophyll-a data using a modified DINEOF method: a case study in the Bohai and Yellow seas, China. Int. J. Rem. Sens. 35, 204-217.

Wang, Y.Q., Liu, D.Y., Tang, D.L., 2017. Application of a generalized additive model (GAM) for estimating chlorophyll-a concentration from MODIS data in the Bohai and Yellow Seas, China. Int. J. Rem. Sens. 38, 639-661.

Wang, Y.Q., Liu, D.Y., Wang, Y.J., Gao, Z.Q., Keesing, J.K., 2019c. Evaluation of standard and regional satellite chlorophyll-a algorithms for moderate-resolution imaging spectroradiometer (MODIS) in the Bohai and Yellow Seas, China: a comparison of chlorophyll-a magnitude and seasonality. Int. J. Rem. Sens. 40, 4980-4995.

Weatherhead, E.C., Harder, J., Araujo-Pradere, E.A., Bodeker, G., English, J.M., Flynn, L. E., Frith, S.M., Lazo, J.K., Pilewskie, P., Weber, M., Woods, T.N., 2017. How long do satellites need to overlap? Evaluation of climate data stability from overlapping satellite records. Atmos. Chem. Phys. 17, 15069-15093.

Wei, H., Shi, J., Lu, Y.Y., Peng, Y.A., 2010. Interannual and long-term hydrographic changes in the Yellow Sea during 1977-1998. Deep-Sea Res. Part II Top. Stud. Oceanogr. 57, 1025-1034.

Wei, H., Sun, J., Moll, A., Zhao, L., 2004. Phytoplankton dynamics in the Bohai Sea observations and modelling. J. Mar. Syst. 44, 233-251.

Wei, Q., Yao, Q., Wang, B., Wang, H., Yu, Z., 2015. Long-term variation of nutrients in the southern Yellow Sea. Continent. Shelf Res. 111, 184-196.

Wei, Q.S., Yu, Z.G., Wang, B.D., Fu, M.Z., Xia, C.S., Liu, L., Ge, R.F., Wang, H.W., Zhan, R., 2016. Coupling of the spatial-temporal distributions of nutrients and physical conditions in the southern Yellow Sea. J. Mar. Syst. 156, 30-45.

Werdell, P.J., Bailey, S.W., Franz, B.A., Harding Jr., L.W., Feldman, G.C., McClain, C.R., 2009. Regional and seasonal variability of chlorophyll-a in Chesapeake Bay as observed by SeaWiFS and MODIS-Aqua. Rem. Sens. Environ. 113, 1319-1330.
Wu, R.H., Lin, J.M., Li, B., 2016. Spatial and temporal variability of sea surface temperature in eastern marginal seas of China. Adv. Meteorol. 1-9, 2016.

Wu, Z., Huang, N.E., Chen, X., 2009. The multi-dimensional ensemble empirical mode decomposition method. Adv. Adapt. Data Anal. 1, 339-372.

Wu, Z., Huang, N.E., Long, S.R., Peng, C.-K., 2007. On the trend, detrending, and variability of nonlinear and nonstationary time series. Proc. Natl. Acad. Sci. Unit. States Am. 104, 14889-14894.

Xiao, L., Zhao, R., 2017. China's new era of ecological civilization. Science 358, 1008-1009.

Xin, M., Wang, B., Xie, L., Sun, X., Wei, Q., Liang, S., Chen, K., 2019. Long-term changes in nutrient regimes and their ecological effects in the Bohai Sea, China. Mar. Pollut. Bull. 146, 562-573.

Xing, Q., Tosi, L., Braga, F., Gao, X., Gao, M., 2015. Interpreting the progressive eutrophication behind the world's largest macroalgal blooms with water quality and ocean color data. Nat. Hazards 78, 7-21.

Yamaguchi, H., Ishizaka, J., Siswanto, E., Son, Y.B., Yoo, S., Kiyomoto, Y., 2013. Seasonal and spring interannual variations in satellite-observed chlorophyll-a in the Yellow and East China Seas: new datasets with reduced interference from high concentration of resuspended sediment. Continent. Shelf Res. 59, 1-9.

Yamaguchi, H., Kim, H.-C., Son, Y.B., Kim, S.W., Okamura, K., Kiyomoto, Y., Ishizaka, J., 2012. Seasonal and summer interannual variations of SeaWiFS chlorophyll a in the Yellow Sea and East China sea. Prog. Oceanogr. 105, 22-29.

Yanagi, T., Takahashi, S., 1993. Seasonal variation of circulations in the East China Sea and the Yellow Sea. J. Oceanogr. 49, 503-520.

Yang, F., Wei, Q., Chen, H., Yao, Q., 2018. Long-term variations and influence factors of nutrients in the western North Yellow Sea, China. Mar. Pollut. Bull. 135, 1026-1034.

Yoder, J.A., Kennelly, M.A., 2003. Seasonal and ENSO variability in global ocean phytoplankton chlorophyll derived from 4 years of SeaWiFS measurements. Global Biogeochem. Cycles 17, 1112.

Zhai, F., Wu, W., Gu, Y., Li, P., Song, X., Liu, P., Chen, Y., He, J., 2021. Interannualdecadal variation in satellite-derived surface chlorophyll-a concentration in the Bohai Sea over the past 16 years. J. Mar. Syst. 215, 103496.

Zhang, H.L., Qiu, Z.F., Sun, D.Y., Wang, S.Q., He, Y.J., 2017. Seasonal and interannual variability of satellite-derived chlorophyll-a (2000-2012) in the Bohai Sea, China. Rem. Sens. 9, 582.

Zhang, M., Zhang, Y., Shu, Q., Zhao, C., Wang, G., Wu, Z., Qiao, F., 2018. Spatiotemporal evolution of the chlorophyll a trend in the North Atlantic ocean. Sci. Total Environ. 612, 1141-1148.

Zheng, C.W., Zhang, R., Shi, W.L., Li, X., Chen, X., 2017. Trends in significant wave height and surface wind speed in the China Seas between 1988 and 2011. J. Ocean Univ. China 16, 717-726. 